\title{
Imaging Guidance for Therapeutic Delivery: The Dawn of Neuroenergetics
}

\author{
Vilakshan Alambyan ${ }^{1} \cdot$ Jonathan Pace ${ }^{2}$ Persen Sukpornchairak ${ }^{2} \cdot$ Xin $_{\mathrm{Yu}^{3,4,5}} \cdot$ Hamza Alnimir $^{2} \cdot$ Ryan Tatton $^{3}$. \\ Gautham Chitturu $^{6}$ - Anisha Yarlagadda ${ }^{6}$. Ciro Ramos-Estebanez ${ }^{2}$ (D)
}

Published online: 2 April 2020

(C) The American Society for Experimental NeuroTherapeutics, Inc. 2020

\begin{abstract}
Modern neurocritical care relies on ancillary diagnostic testing in the form of multimodal monitoring to address acute changes in the neurological homeostasis. Much of our armamentarium rests upon physiological and biochemical surrogates of organ or regional level metabolic activity, of which a great deal is invested at the metabolic-hemodynamic-hydrodynamic interface to rectify the traditional intermediaries of glucose consumption. Despite best efforts to detect cellular neuroenergetics, current modalities cannot appreciate the intricate coupling between astrocytes and neurons. Invasive monitoring is not without surgical complication, and noninvasive strategies do not provide an adequate spatial or temporal resolution. Without knowledge of the brain's versatile behavior in specific metabolic states (glycolytic vs oxidative), clinical practice would lag behind laboratory empiricism. Noninvasive metabolic imaging represents a new hope in delineating cellular, nigh molecular level energy exchange to guide targeted management in a diverse array of neuropathology.
\end{abstract}

Keywords Brain metabolism $\cdot$ Metabolic imaging $\cdot$ MRI $\cdot$ Neurocritical care $\cdot$ Neuroenergetics $\cdot$ Stroke

\section{Introduction}

Brain energy requirements approach $20 \%$ of the body's requirements [1]. The nonlinear expansion of the neocortex and higher cognition imparted a genetic framework necessary

Issue theme Neurocritical Care: Bench to Bedside or Imaging Guidance for Therapeutic Delivery.

Ciro Ramos-Estebanez

cramoses@icloud.com

1 Department of Neurology, Albert Einstein Medical Center, Philadelphia, Pennsylvania, USA

2 Neurological Institute, University Hospitals Cleveland Medical Center, Case Western Reserve University, Cleveland, Ohio, USA

3 Department of Biomedical Engineering, Case Western Reserve University, Cleveland, Ohio, USA

4 Department of Radiology, Case Western Reserve University, Cleveland, Ohio, USA

5 Department of Physiology and Biophysics, Case Western Reserve University, Cleveland, Ohio, USA

6 Department of Arts and Sciences, Case Western Reserve University, Cleveland, Ohio, USA for energy metabolism to address this need [2]. For example, adult brain aerobic glycolysis localizes to and accounts for approximately $25 \%$ of glucose utilization in the dorsolateral prefrontal cortex, the superior and medial frontal gyrus, or the precuneus and posterior cingulate cortex $[3,4]$. Separate lines of inquiry into brain neuroenergetics suggest differential astrocyte-neuron interactions, recruitment of subcellular elements, production of metabolic intermediaries, and a subsequent task-dependent allocation [5].

Roy and Sherrington's hypothesis of a coupling mechanism between the local vascular supply, functional activity, and the "chemical products" continues to influence [6-12] surrogate markers of neuronal activity from blood flow and metabolism to inform positron emission tomography (PET) and fMRI approaches [13-15]. PET estimates distribution of tracers labeled with positron-emitting isotopes $\left({ }^{18} \mathrm{~F}\right.$ or $\left.{ }^{15} \mathrm{O}\right)$ to yield measurements of cerebral blood flow (CBF) using $\mathrm{H}_{2}{ }^{15} \mathrm{O}$ or oxygen consumption from ${ }^{15} \mathrm{O}_{2}$ and glucose utilization with ${ }^{18}$ F-labeled 2-deoxyglucose (FDG), respectively. fMRI reflects the endogenous changes in oxy- and deoxyhemoglobin ratios following activity-dependent processes related to changes in $\mathrm{CBF}$ and cerebral blood volume $[1,16]$. Although fMRI and PET can detect energy delivery and use signals of neuronal activity, additional insights at the 
cellular neuroenergetics (especially oligodendrocytes and microglia) are necessary to guide diagnostics of metabolic states and neurotherapeutic targets.

For instance, whole-brain steady-state arterial-venous gradients indicate that glucose is almost entirely oxidized to $\mathrm{CO}_{2}$ and $\mathrm{H}_{2} \mathrm{O}$. PET, autoradiographic 2-DG method, and magnetic resonance imaging (MRI)-mediated analyses of local/regional glucose utilization, $\mathrm{O}_{2}$ consumption, and $\mathrm{CBF}$, however, point toward an uncoupling between glucose uptake and oxygen consumption over activated cortical areas. An increase in $\mathrm{CBF}$ and in glucose utilization is not matched by an equivalent increase in oxygen consumption, thereby raising the possibility that, during the early stages of activation, increased energy demand is met by glycolysis rather than by oxidative phosphorylation [17-21]. This has triggered the development of additional imaging substrates with faithful spatial and temporal resolution of neuroenergetics (Fig. 1).

Consequently, more advanced techniques have emerged to inform intraparenchymal targets at the regional, cellular, and molecular levels. For example, magnetic resonance spectroscopy (MRS) quantifies metabolic fluxes in vivo using stable isotopes such as ${ }^{13} \mathrm{C}$ and ${ }^{1} \mathrm{H}[23,24]$. Ongoing nuclear magnetic resonance (NMR) work on ${ }^{31} \mathrm{P}$ focuses on directly measuring ATP synthesis [25-27]. Elsewhere, homogeneous preparations of neurons and astrocytes, i.e., primary cultures or single-cell analyses [28-30] as well as nanosensors/ fluorescent analogs [31-33] targeting specific metabolites, aim to disentangle the relative contributions of each cell type to the metabolic processes scrutinized by PET, fMRI, and MRS.

Cellular level methods only characterize a small portion of the brain, and whole-brain neuroimaging techniques do not possess adequate specificity for neural pathways or signaling components [34]. Albeit lucrative, fMRI is also limited with significant room for false positives and negatives [35-38]. Molecular imaging, therefore, has a future in the important clinical goals of 1) early detection of disease, 2) optimization of therapy for specific molecular targets, 3) predicting and monitoring response to therapy, 4) monitoring for disease recurrence, and finally, 5) augmentation of drug discovery and validation processes. Specifically, molecular probe fMRI could enhance brain-wide neurochemical maps to provide fundamental insights into the relationships between neurotransmitter release, cognitive phenomena, affective states, and diseases, at the individual cell level.

This review probes the place of neuroimaging at different levels of central nervous system (CNS) organization and heralds the MRI in estimation of cerebral metabolism, especially its potential role in precision neurocritical care.
Fig. 1 Resolution and invasiveness among brain metabolic measurement techniques. Comparisons of spatial resolution, temporal resolution, and invasiveness among various techniques used to measure brain metabolism. Modified from Hyder and Rothman [22] (Advances in imaging brain metabolism, Annu Rev Biomed Eng 19:485-515. Copyright (2017), with permission from Annual Reviews)

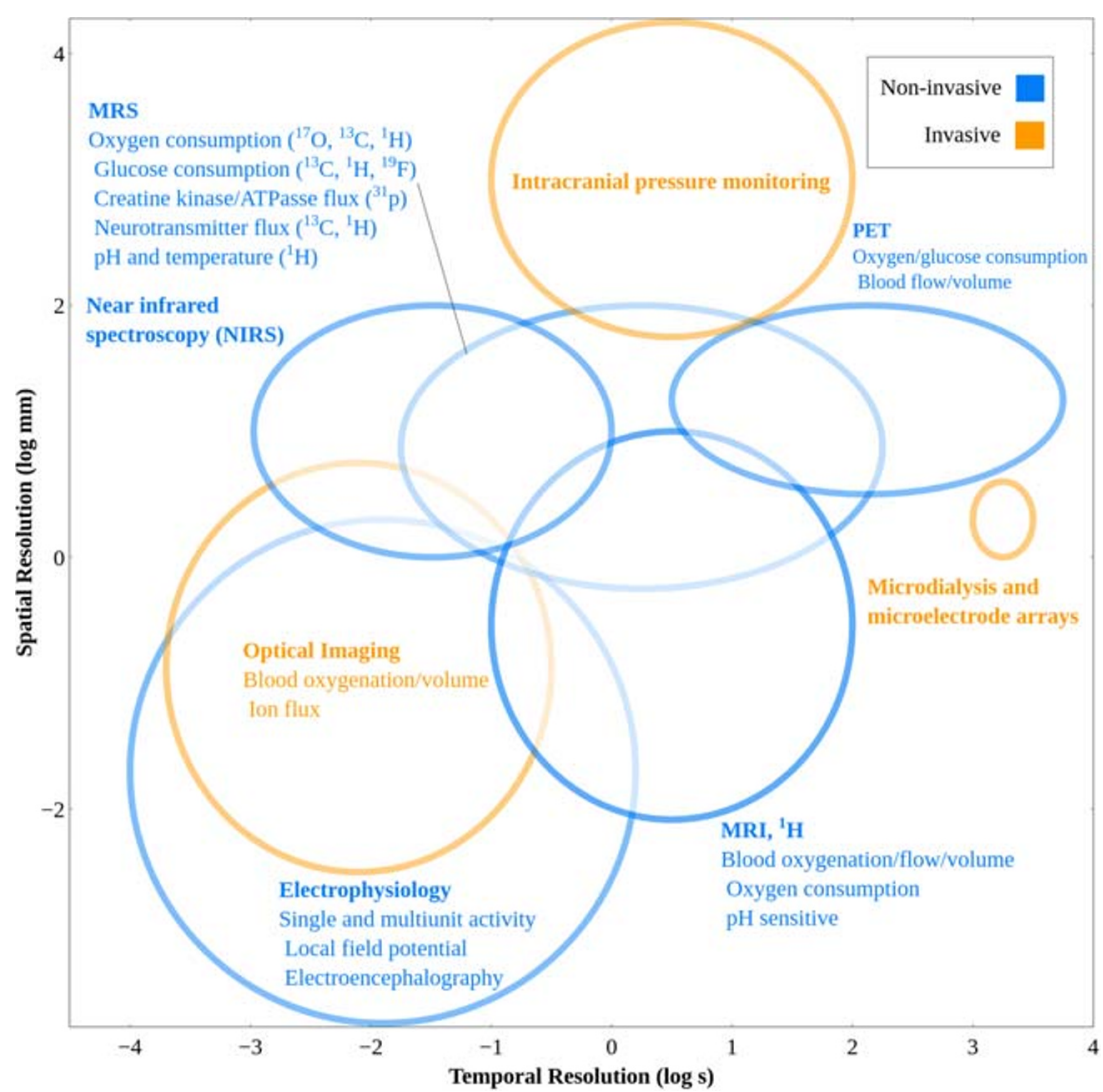




\section{Surrogate Markers of CNS Metabolism}

\section{Organ-Level Hemodynamic Indices}

In the modern neurocritical care unit, invasive monitoring has remained the mainstay of optimization and management of the critically ill patient. The standard of care still rests on the prevention of secondary insults via an acute maintenance of the hemodynamic milieu [39, 40]. Instrumentation usually involves arterial line placement for continuous blood pressure monitoring, central venous access for the measuring of central pressures, and external ventricular drain placement to calibrate the CNS hydrodynamics.

Longitudinal profiling of neurophysiological parameters (multimodal monitoring) evades widespread acceptance across the neurocritical care spectrum as they await reproducible improvement in outcomes [41]. For instance, we routinely estimate oxygen delivery to the CNS, which in turn is influenced by cardiac output/index, CBF, and oxygen serum content (Fig. 2 ). Although there is limited evidence surrounding direct cardiac output estimation such as pulmonary artery catheter, similar yet less invasive indirect methodologies (e.g., PiCCO (Pulsion Medical Systems, Munich, Germany) monitoring) are slowly becoming the mainstay of volume status optimization [42]. Besides, with the addition of serum hemoglobin and $\mathrm{PaO}_{2}$ values, calculations of serum oxygen content may also be pursued (Fig. 2). Transcranial Doppler monitoring, although routinely used to estimate $\mathrm{CBF}$ in stroke and subarachnoid hemorrhage (SAH) noninvasively [43], is limited given oxygen diffusion across the blood-brain barrier (BBB) and its consumption counterpart $\left(\mathrm{VO}_{2}\right.$, oxygen extraction ratio or fraction (OEF); Fig. 2) connote tissue-level consumption [44].

Besides classic contributions from partial pressure of oxygen, diffusion surface area, and BBB permeability, the local metabolic demand [45-48] is satisfied through cerebral autoregulation and changes in hemoglobin affinity for oxygen driven by the Bohr effect [49-53]. Eventually, to maintain the cortical $\mathrm{PtO}_{2}$ physiological range at 20 to $25 \mathrm{mmHg}$ at rest (up to $48 \mathrm{mmHg}$ during intense exercise), we require more robust explanations beyond hemodynamic parameters to inform tissue-level perfusion and oxygenation $[54,55]$.

\section{Tissue-Level Metabolic Markers}

Preservation of the delicate relationships between the pressures of individual intracranial compartments governed by the Monroe Kellie principle has remained incumbent upon intracranial pressure (ICP) monitoring in neurocritically ill patients for over 50 years. Monitoring at intraparenchymal and intraventricular levels has superseded frequently inaccurate epidural measurements, but subdural monitors are sometimes preferred given the latter's perceived ease of placement and lower risk of complications [41, 56-58].

$$
\begin{aligned}
& \begin{aligned}
C_{a} \mathrm{O}_{2} & =\text { Bound } \mathrm{O}_{2}+\text { Dissolved } \mathrm{O}_{2} \\
& =\left(1.34 \times \mathrm{Hb} \times S_{a} \mathrm{O}_{2} \times 0.01\right)+\left(0.0031 \times P_{a} \mathrm{O}_{2}\right)
\end{aligned} \\
& \begin{aligned}
V \mathrm{O}_{2} & =C O \times\left(C_{a} \mathrm{O}_{2}-C_{v} \mathrm{O}_{2}\right)=Q \times\left[\left(\mathrm{O}_{2}\right)_{\text {in }}-\left(\mathrm{O}_{2}\right)_{\text {out }}\right]
\end{aligned} \\
& V \mathrm{O}_{2} I=C I \times\left(C_{a} \mathrm{O}_{2}-C_{v} \mathrm{O}_{2}\right) \\
& \text { Peripheral: } \mathrm{O}_{2} E R=\frac{C_{a} \mathrm{O}_{2}-C_{v} \mathrm{O}_{2}}{C_{a} \mathrm{O}_{2}} \\
& \text { Tissue level: } \mathrm{O}_{2} E R=\frac{\left(\mathrm{O}_{2}\right)_{\text {in }}-\left(\mathrm{O}_{2}\right)_{\text {out }}}{\left(\mathrm{O}_{2}\right)_{\text {in }}} \\
& \text { OEF }=\frac{C M R \mathrm{O}_{2}}{C_{a} \mathrm{O}_{2} \times C B F}
\end{aligned}
$$

Fig. 2 Laws governing oxygen transaction to the brain. Equation 1: $\left(\mathrm{C}_{\mathrm{a}} \mathrm{O}_{2}\right)=$ Arterial oxygen content. $\mathrm{Hb}=$ Hemoglobin concentration. $\mathrm{S}_{\mathrm{a}} \mathrm{O}_{2}=$ Arterial oxygen saturation. $\mathrm{P}_{\mathrm{a}} \mathrm{O}_{2}=$ Arterial oxygen partial pressure; 0.0031 represents the solubility coefficient of oxygen. Each gram of hemoglobin is capable of carrying $1.34 \mathrm{ml}$ of oxygen. Equation2: $\mathrm{VO}_{2}=$ Oxygen consumption. $\mathrm{CO}=$ Cardiac output. $\mathrm{C}_{\mathrm{a}} \mathrm{O}_{2}=$ Arterial oxygen content. $\mathrm{C}_{\mathrm{v}} \mathrm{O}_{2}=$ Venous $\mathrm{O}_{2}$ content. $\mathrm{Q}=$ blood flow. $\left(\mathrm{O}_{2}\right)$ in $=$ the oxygen content of the afferent blood (analogous to $\mathrm{C}_{\mathrm{a}} \mathrm{O}_{2}$ globally $).\left(\mathrm{O}_{2}\right)$ out $=$ the oxygen content of the efferent blood (analogous to $\mathrm{C}_{\mathrm{v}} \mathrm{O}_{2}$ globally). Equation 3: $\mathrm{VO}_{2} \mathrm{I}=$ Oxygen consumption index. $\mathrm{CI}=$ Cardiac index. $\mathrm{C}_{\mathrm{a}} \mathrm{O}_{2}=$ Arterial oxygen content. $\mathrm{C}_{\mathrm{v}} \mathrm{O}_{2}=$ Venous $\mathrm{O}_{2}$ content. Equation 4: $\mathrm{O}_{2} \mathrm{ER}=$ Oxygen extraction ratio, which is the proportion of arterial oxygen that is removed from the blood as it passes through the microcirculation. $\mathrm{C}_{\mathrm{a}} \mathrm{O}_{2}$ $=$ Arterial oxygen content. $\mathrm{C}_{\mathrm{v}} \mathrm{O}_{2}=$ Venous $\mathrm{O}_{2}$ content. Equation 5: $\mathrm{O}_{2} \mathrm{ER}$ = Oxygen extraction ratio. $\left(\mathrm{O}_{2}\right)$ in $=$ the oxygen content of the afferent blood (analogous to $\mathrm{C}_{\mathrm{a}} \mathrm{O}_{2}$ globally). $\left(\mathrm{O}_{2}\right)$ out $=$ the oxygen content of the efferent blood (analogous to $\mathrm{C}_{\mathrm{v}} \mathrm{O}_{2}$ globally). Equation 6: $\mathrm{OEF}=$ Oxygen extraction fraction. $\mathrm{CMRO}_{2}=$ Cerebral metabolic rate of oxygen. $\mathrm{C}_{\mathrm{a}} \mathrm{O}_{2}=$ Arterial oxygen content. $\mathrm{CBF}=$ Cerebral blood flow

In its natural progression, invasive intracranial monitoring of regional as well as tissue-level activity allows continuous measurements and the ability to titrate therapy for elevated $\mathrm{ICP}$, decreased brain tissue oxygenation $\left(\mathrm{PbtO}_{2}\right)$, and metabolic derangements [59]. Nevertheless, this approach is limited by its inherent local nature and surgical complications.

Brain tissue oxygenation $\left(\mathrm{PbtO}_{2}\right)$ pursues optimization of brain oxygenation in the setting of tissue ischemia [60] when coupled with ICP monitoring and perfusion monitoring and may also be useful in the prevention of secondary injury [61]. Current $\mathrm{PbtO}_{2}$ monitors share important limitations of their invasive insertion, calibration requirements, caducity, and necessity for precise placement given the limited area of tissue sampled (i.e., 14-24 $\mathrm{mm}^{2}$ with Licox (Integra LifeSciences, Plainsboro, NJ) and Neurovent (Raumedic AG + CO, Raumedic, Germany) probes). Contemporary evidence has also examined the utility of intraparenchymal monitors through extrapolation of global $\mathrm{CBF}$ from regional $\mathrm{CBF}$ by CT perfusion imaging [62]. Although promising, this may not fully characterize regional microvascular alterations and 
subsequent oxygen extraction or utilization, thereby current consensus endorses the use of $\mathrm{PbtO}_{2}$ monitoring in neurocritical care patients at risk of hypoxia [41].

Current attempts to quantify tissue-level behavior of glucose and its metabolic intermediaries, amino acids, enzymes, ions, proteins, and signaling molecules etc. through microdialysis assays lack temporal and spatial resolution (Fig. 3) [63]. Spatial resolution is limited by the probe length of 1 to $4 \mathrm{~mm}$, whereas temporal resolution may be restricted to $20 \mathrm{~min}$ per sample or more [64]. Relevant advancements in "minimally invasive" microfabricated probe technology could improve spatial resolution and encourage comprehensive inquiry of the interstitial space [65-67].

\section{Noninvasive Monitoring Adjuncts}

Prima facie, noninvasive strategies such as optical imaging tools in tandem with electrophysiological measurements have emerged to detect dynamic changes in brain metabolism and neurochemistry after brain injury. Near infrared spectroscopy or diffuse correlation spectroscopy estimates regional deoxyhemoglobin and oxyhemoglobin concentration [68] and cerebral blood flow [69]. However, it cannot provide insight on the overall brain activity or at deep structure level. Other noninvasive methods include measurements of the diameters of the ophthalmic artery, intracranial vessels, and optic nerve sheath diameter [70-72]. In summary, noninvasive ICP evaluations require serial examinations performed with minimal variability.

Given the strict correlation of summative postsynaptic potentials with neurovascular energy units, continuous electroencephalography (EEG) as well as somatosensory-evoked potentials (SSEP) may reflect pathological energy states involving post-arrest, severe traumatic brain injury (TBI), as well as SAH populations. The presence or absence of low voltage or isoelectric EEG, as well as the presence or absence of SSEPs, may reliably predict poor neurological outcomes in patients following cardiac arrest [73]. Low voltage or isoelectric EEG is $40 \%$ sensitive and $100 \%$ specific, whereas the absence of SSEPs carries $24 \%$ sensitivity and $100 \%$ specificity, respectively [73].

\section{Cellular Level Metabolic Targets}

The brain effectively generates energy through aerobic glycolysis, where lactate (Fig. 3) is consumed distinctly upon regional specialization, rendering discrete cellular metabolic signatures for the neuron and astrocyte (Fig. 4) [74, 75]. Astrocytes are unique in glycogen storage yet possess mitochondria (same as neurons), populate the gray matter (protoplasmic), invest the BBB, and are intimately linked with the neuron [76]. Adult aerobic glycolysis and lactate production are metabolic features of astrocytes, yet marginally expressed in neurons, which retain their oxidative identity (Figs. 3 and 4)
[5]. The majority of neuronal energy expenditure is devoted to synaptic level signaling [77].

Glucose is processed mainly through the oxidative branch, rather than glycolysis, which suggests an antioxidant role in neurons rather than a bioenergy source [1]. This and other arguments in forthcoming section(s) will consolidate the case to revisit the neuron-centric and energy favorite model of glucose metabolism in the neurocritical care unit.

Altogether, there exists a complementary relationship between neurons and astrocytes to process glucose. Lactate, conventionally an anaerobic metabolite, is now hailed as an end product of either glycolytic pathway, derived via pyruvate when oxygen tension is low [78, 79]. Under physiological circumstances, only $10 \%$ of glucose entering the brain from the arterial side yields lactate via aerobic glycolysis, whereas the rest enters the expected oxidative route (Fig. 3) [79]. Neurons, however, uncouple glycolysis and the TCA cycle (i.e., in the presence of both glucose and lactate, neurons preferentially use lactate as their main oxidative substrate) [80, 81]. Accordingly, aerobic glycolysis levels may represent lactate efflux from glycolysis, or a glycogen shunt, to rapidly supply ATP to areas with enhanced demands (e.g., bursting synapses [82] or shape synaptic connections during development [83]). Astrocytes shuttle lactate and pyruvate to neurons sparing the remaining glucose from oxidative phosphorylation and preserving it toward anabolic pathways for synaptic creation/turnover [79, 84]. In its terminal fate then, lactate is being utilized under aerobic conditions, but is prone to cytosolic accumulation with an anaerobic milieu.

This versatility of the CNS metabolic machinery to differentially invoke lactate during physiological states or in the setting of regionally increased metabolic demand spares the neuron from oxidative stress but could not be delineated with an adequate resolution via whole-brain studies (Fig. 4) [1, 85]. Even though fMRI [13] signals coincide spatially with EEG local field potentials (electrical markers of synaptic activity), in vitro and in vivo biochemical and imaging evidence suggest 1) the major neuroenergetic burden is synaptic, 2) molecular mechanisms couple synaptic activity to local energy delivery with astrocytes as a facilitator, and 3) cell-specific expression and activity profiles allow for a limited aerobic glycolysis but a robust TCA cycle and oxidative phosphorylation in neurons. Conversely, astrocytes are favorable toward glycolysis which can be upregulated, whereas pyruvate processing in the TCA cycle is limited under normal oxygen tension (Fig. 5) [86, 87].

Brain activity mapping beyond neurovascular coupling cannot obtain single-cell resolution. This is secondary to fundamental neurovascular distances and the multicentric origin of functional imaging signals (Fig. 6). Any combination of excitation, inhibition, or neuromodulation can generate blood-oxygen level-dependent (BOLD) responses. But, we cannot estimate the contribution of each, scale input-output relationships among activated areas or extrapolate the 


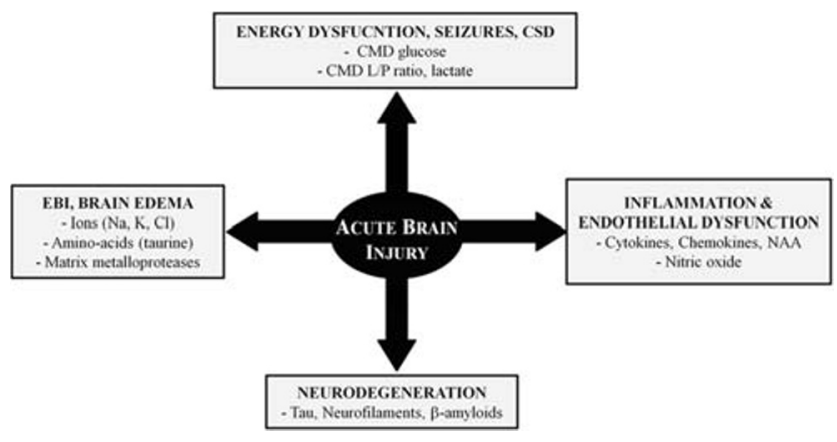

Fig. 3 Metabolic targets in microdialysis monitoring. $C M D$ cerebral microdialysis, CSD cortical spreading depressions, $E B I$ early brain injury, $L / P$ lactate/pyruvate, $N A A$, n-acetyl aspartate. Reprinted from Carteron (Neurointensive Care Therapy: An Update of Recent Clinical Data. Front Neurol. 2017;8:601. Copyright (2017). Creative Commons license 4.0 (CC BY 4.0)

amplitude and duration of neural processes from hemodynamic changes in real time $[88,89]$.

\section{Metabolic Imaging Markers}

\section{Penumbral Markers}

Ischemic penumbra, beyond its initial description by Astrup in 1981, represents perfused brain tissue with residual subcellular integrity but impaired electrical function [90] and the potential to recover if perfusion is improved. A cerebral blood vessel once occluded triggers a cascade of pathophysiological events dispersed in time and space. As blood flow falls below 16 to $18 \mathrm{ml} / 100 \mathrm{~g} / \mathrm{min}$ (the "higher" threshold) [91, 92], an instantaneous cessation of electrical activity occurs. Local blood flow must fall below $10 \mathrm{ml} / 100 \mathrm{~g} / \mathrm{min}$ (the "lower" threshold) to perturb the otherwise steady energy state and ion homeostasis [93]. Even diminutive supportive blood flow by collaterals protects the penumbra surrounding the ischemic core from a critical energy imbalance associated with neuronal death if blood supply can be restored soon [94, 95]. Patterns that predict a good response to thrombolytic therapy have small volumes of core and large volumes of penumbra.

\section{Computed Tomography}

Parenchymal hypoattenuation on noncontrast computed tomography has been associated with a predilection for infarction on PET and with an "infarct core" on CT perfusion imaging. Conversely, sulcal effacement without hypoattenuation secondary to an elevated cerebral blood volume signifies "penumbral" perfusion. However, noncontrast computed tomography in isolation is extremely limited for penumbral evaluation in the acute or hyperacute setting [96].
Next, despite its logistical appeal, CT perfusion imaging is hindered by poor cardiac output, atrial fibrillation, severe proximal arterial stenosis, or poor placement of arterial and venous density regions of interest [97]. Thus, it may underestimate the CBF, overestimate the MTT, and yield inaccurate perfusion maps. Additionally, the focus on basal ganglia and supraganglionic elements ignores the posterior fossa and superior cerebral hemispheres. Low spatial resolution excludes lacunar infarcts, whereas a relative hyperemia of an ictal region can introduce a false positive infarct of the contralateral hemisphere [98].

\section{Magnetic Resonance Imaging}

Mutatis mutandi, MRI represents exciting avenues for precision medicine tailored to a diverse array of disease states. It heralds a new era of subcellular and potentially molecular level neuroenergetics in combination with other technologies.

Despite MRI's inherent temporal resolution limitation, its noninvasive nature precludes risks such as misplacement, infection (with its associated costs), decalibration, and hemorrhage. Moreover, among noninvasive approaches, it is nonradioactive, and it allows for regional resolution. Depending on the sequence, both extraparenchymal and parenchymal level metabolic assessments are available. Perturbations of oxygen consumption at the neurovascular unit are paramount toward understanding neurological disease processes [99-104]. Likewise, stroke remains the flagship model for applying neuroimaging toward a biochemical basis of energy metabolism [105].

Fundamentally, the penumbra and ischemic core are defined by metabolic parameters such as the $\mathrm{CBF}, \mathrm{OEF}$, arterial oxygen content and their derivatives such as cerebral metabolic rate of oxygen $\left(\mathrm{CMRO}_{2}\right)$, and the recent oxygen metabolic index (OMI). With reduced CBF, OEF can increase to maintain normal oxygen metabolism. At maximal oxygen extraction, further reduction in $\mathrm{CBF}$ leads to a decrease in $\mathrm{CMRO}_{2}$. Severe reduction in $\mathrm{CMRO}_{2}$ will lead to cell death. Therefore, imaging methods that can quantify $\mathrm{CBF}, \mathrm{OEF}, \mathrm{OMI}$, and $\mathrm{CMRO}_{2}$ may allow the differentiation of the penumbra and infarct core [106].

The imaging techniques undergoing the most rigorous assessment are perfusion- and diffusion-weighted MRI, i.e., PWI and DWI. Although PWI is effective in identifying regions with perfusion deficits, DWI is sensitive to cytotoxic edema. DWI lesions often represent infarct core, and regions with a PWI deficit yet normal DWI are regarded as the salvageable penumbra (perfusion-diffusion mismatch). However, clinical trials that relied on perfusion-diffusion mismatch failed to show benefits of MRI-based patient selection for thrombolysis [107]. Further, a combined MRI and PET study on acute stroke found considerable variability in the extent of $\mathrm{CMRO}_{2}$ reduction in regions with abnormal DWI, 


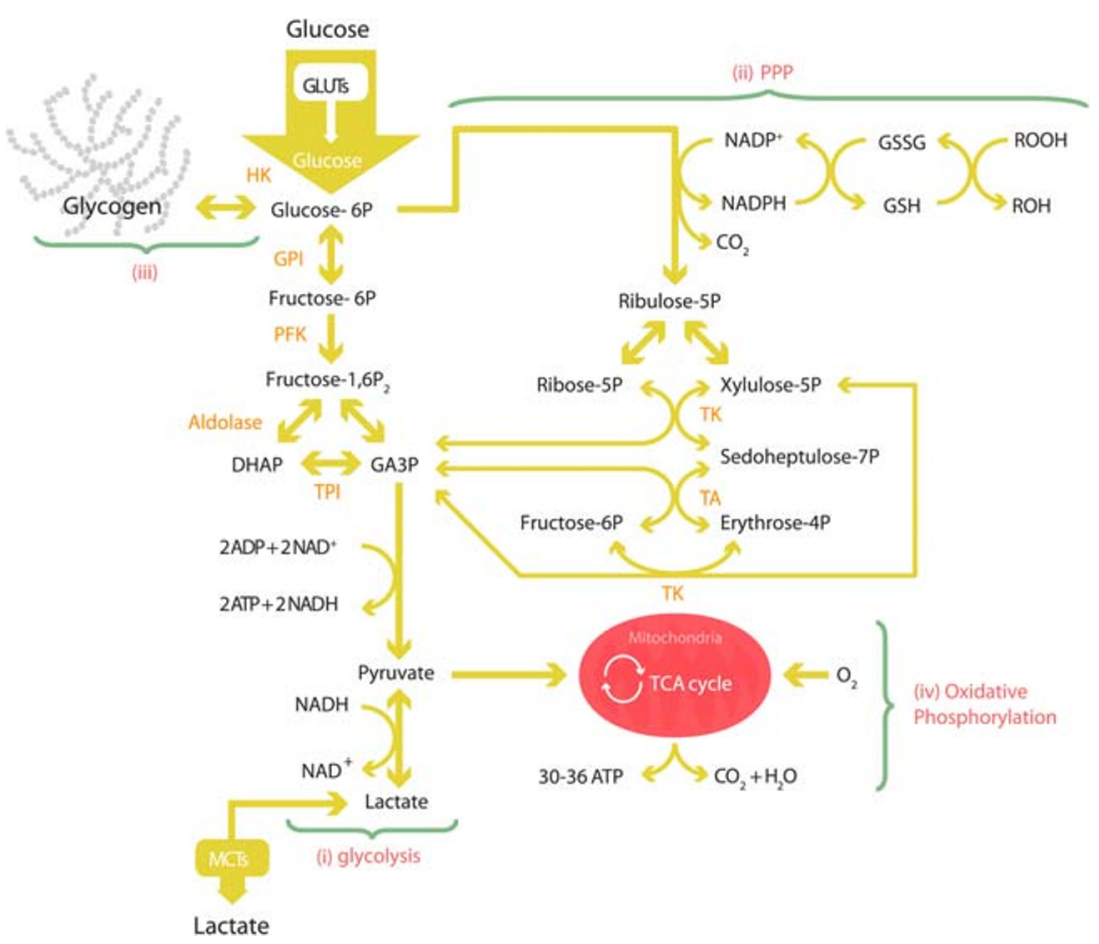

Fig. 4 General depiction of brain metabolism. Diagram of glucose metabolism. Glucose can be processed through 3 main metabolic pathways. The first metabolic pathway is glycolysis (i), which gives rise to 2 molecules of pyruvate as well as one molecule of ATP and $\mathrm{NADH}$ each. Then, this pyruvate enters the mitochondria, where it is metabolized through the tricarboxylic acid cycle and oxidative phosphorylation, producing ATP and $\mathrm{CO}_{2}$ using oxygen as electron acceptor (iv). Lactate dehydrogenase, during hypoxia or depending on the cellular metabolic profile, reduces pyruvate to lactate, which can be liberated to extracellular by monocarboxylate transporter. Compared to glycolysis (2 ATPs), the complete oxidation of glucose produces larger

indicating that DWI lesions may not always represent irreversibly damaged tissue [108]. This observation is supported by the reversal of diffusion abnormalities via thrombolysis within $6 \mathrm{~h}$ of symptom onset [109]. Such findings question the assumed equivalence of a DWI lesion to ischemic core.

Perfusion-diffusion mismatch aims to identify 2 different metabolic regions, i.e., regions with electrical failure, but preserved energy state (penumbra) versus regions with compounded electrical and energy failure (infarct core). However, it does not address cellular neuroenergetics beyond the oxidative fate of glucose (oxygen consumption rate or $\mathrm{CBF}$ ) in the neuron [90] and cannot account for the neurovascular coupling mediated by astrocytes, i.e., glycolysis (Fig. 3). More importantly, PWI imaging is a snapshot which does not reflect the dynamic nature of the penumbra. Furthermore, the use of a single threshold in determining the mismatch cannot account for the metabolic and physiological heterogeneity of brain tissue. In view of such limitations, interest lies evermore in developing metabolic imaging techniques which better quantitate the penumbra [96]. amounts of energy in the form of ATP in the mitochondria (30-36 ATPs). Alternatively, the pentose phosphate pathway (PPP) can process the glucose-6P (ii), leading to the production of reducing equivalents in the form of NADPH, which is important for defense against oxidative stress. Then, the glutathione reductase uses NADPH as an electron donor to recycle back the oxidized glutathione (GSSG) formed to glutathione. In astrocytes, glucose-6P can also be used to store glucosyl units as glycogen (iii). Reprinted from Magistretti and Allaman [1] (A cellular perspective on brain energy metabolism and functional imaging. Neuron 86:883-901. Copyright (2015), with permission from Elsevier)

Nevertheless, patients with acute ischemic stroke (AIS) within 6 to $24 \mathrm{~h}$ of last known well and large vessel occlusion in the anterior circulation are now frequently selected for mechanical thrombectomy through CTP or DW-MRI, with or without MRI perfusion [110]. Moreover, the 2019 update to ASA/AHA stroke guidelines endorses MRI to identify diffusion-positive FLAIR-negative lesions (DWI-FLAIR mismatch) for IVtPA administration within $4.5 \mathrm{~h}$ of stroke symptom recognition in or AIS patients who awake with stroke symptoms or have unclear time of onset $>4.5 \mathrm{~h}$ from last known well or at baseline state [111].

\section{An Appraisal of Oxygen as a Metabolic Marker}

\section{Oxygen-15 Positron Emission Tomography of Oxygen Metabolism}

Quantification of regional changes in cerebral hemodynamics and metabolism was made possible by PET using oxygen-15 $\left({ }^{15} \mathrm{O}\right)$ and carbon-11 $\left({ }^{11} \mathrm{C}\right)$ radiotracers [112]. These 
Neuron

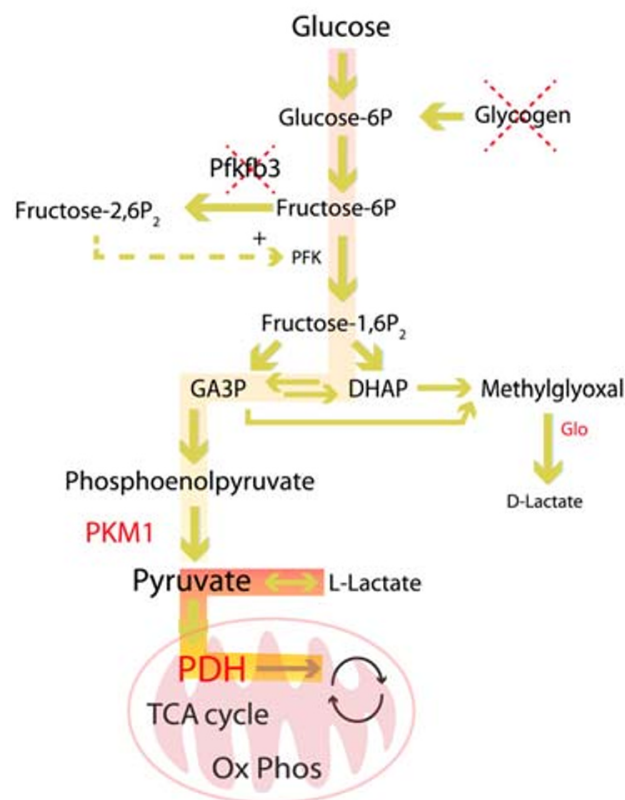

Fig. 5 Differential cellular metabolic signatures. Main different features in metabolic profiles between neurons and astrocytes. Astrocytes are the only cells in the brain that store glycogen, which can be seen by the high levels of expression and activity of Pfkfb3 in astrocytes. On the other hand, the reduced expression and activity of $\mathrm{Pfkfb} 3$ in neurons demonstrates that neurons do not store any glycogen. Cell-specific differential splicing of pyruvate kinase results in the expression of the PKM1 isoform in neurons and the expression of the PKM2 isoform in astrocytes. Additionally, due to pyruvate dehydrogenase's high degree of phosphorylation in neurons, it has more activity in neurons than in astrocytes. These cell-specific expression and activity profiles result in

techniques allowed for the first time novel measurements of regional $\mathrm{CBF}(\mathrm{rCBF})$ using ${ }^{15} \mathrm{O}$-water or ${ }^{15} \mathrm{O}$-carbon dioxide and regional cerebral blood volume using ${ }^{15} \mathrm{O}$-carbon monoxide [113]. More importantly, regional OEF and $\mathrm{CMRO}_{2}$ $\left(\mathrm{rCMRO}_{2}\right)$ measures have been obtained by estimating the conversion of inhaled ${ }^{15} \mathrm{O}$-oxygen gas to ${ }^{15} \mathrm{O}$-water, the last step in oxidative metabolism [114]. Early ${ }^{15} \mathrm{O}$-PET studies on acute stroke $[115,116]$ provided operational criteria for ischemic penumbra identification as characterized by a reduced CBF but preserved $\mathrm{CMRO}_{2}$ and elevated OEF [117]. Lenzi et al. [116] demonstrated that a diminutive $\mathrm{rCMRO}_{2}$ in the core of an acute stroke in general correlated well with the general outcome at a later stage. Patients with a poor clinical outcome had an $\mathrm{rCMRO}_{2}$ lower than $1.25 \mathrm{ml} \mathrm{O} / 100 \mathrm{ml} / \mathrm{min}$ at the acute stage (Fig. 7) [116]. PET earned validation though its ability to outline clinically small infarct cores (i.e., cellular level necrosis) and large volumes of penumbra as the favored pattern for reperfusion in patients with stroke $[118,119]$. These observations further support tissue-level metabolism as the missing link between reduced blood supply and tissue viability $[115,120-122]$.
Astrocyte

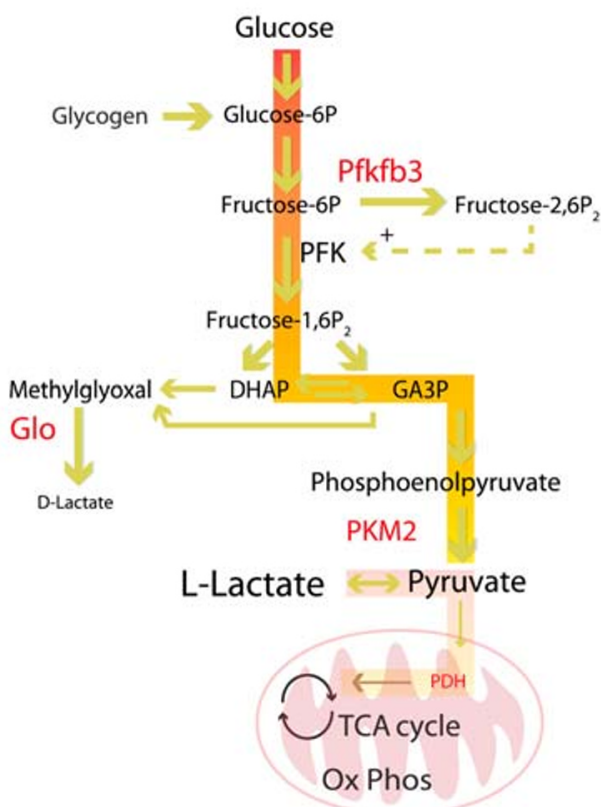

opposing effects in neurons and in astrocytes. In neurons, there is a limited capacity glycolysis and an active TCA cycle as well as oxidative phosphorylation in neurons. On the other hand, in astrocytes, there is a more active glycolysis, which can be upregulated, and a TCA cycle that is limited in capacity due to the nature of its pyruvate processing. Furthermore, in astrocytes, the expression and activity of the glyoxalase system, which can detoxify cells of methylglyoxal, are considerably higher. Reprinted from Magistretti and Allaman [1] (A cellular perspective on brain energy metabolism and functional imaging. Neuron 86:883-901. Copyright (2015), with permission from Elsevier)

However, ${ }^{15} \mathrm{O}-\mathrm{PET}$ requires an expensive on-site cyclotron to generate the short-lived ${ }^{15} \mathrm{O}$ isotope $(\sim 2 \mathrm{~min}$ half-life $)$. When performing inhalation studies using ${ }^{15} \mathrm{O}$ gas, radioactivity from ${ }^{15} \mathrm{O}$-labeled substrate $\left({ }^{15} \mathrm{O}\right.$-oxygen gas) and product $\left({ }^{15} \mathrm{O}\right.$-water) will be detected without distinction. As such, quantification of metabolic parameters $\left(\mathrm{CMRO}_{2}\right.$ and $\left.\mathrm{OEF}\right)$ from PET measurements of radioactivity requires a compartment model to account for tracer delivery and the washout of ${ }^{15} \mathrm{O}$-water generated from oxidative metabolism. For accurate quantification of $\mathrm{CMRO}_{2}$ and $\mathrm{OEF}$, arterial blood sampling is frequently performed to provide input data for the tracer kinetic model. These factors limit the use of ${ }^{15} \mathrm{O}-\mathrm{PET}$ as a clinical tool for metabolic evaluation of ischemic stroke.

\section{Oxygen-17 Magnetic Resonance Imaging of Oxygen Metabolism}

Inspired by ${ }^{15} \mathrm{O}-\mathrm{PET}$, in vivo ${ }^{17} \mathrm{O}-\mathrm{MRI}$ underwent inspection for assessing cerebral metabolism in the late 1980s [123-125].

${ }^{17} \mathrm{O}$ 's stable isotope property allows $\mathrm{H}_{2}{ }^{17} \mathrm{O}$ 's utility as a nontoxic, nonradioactive tracer that can accurately measure water 


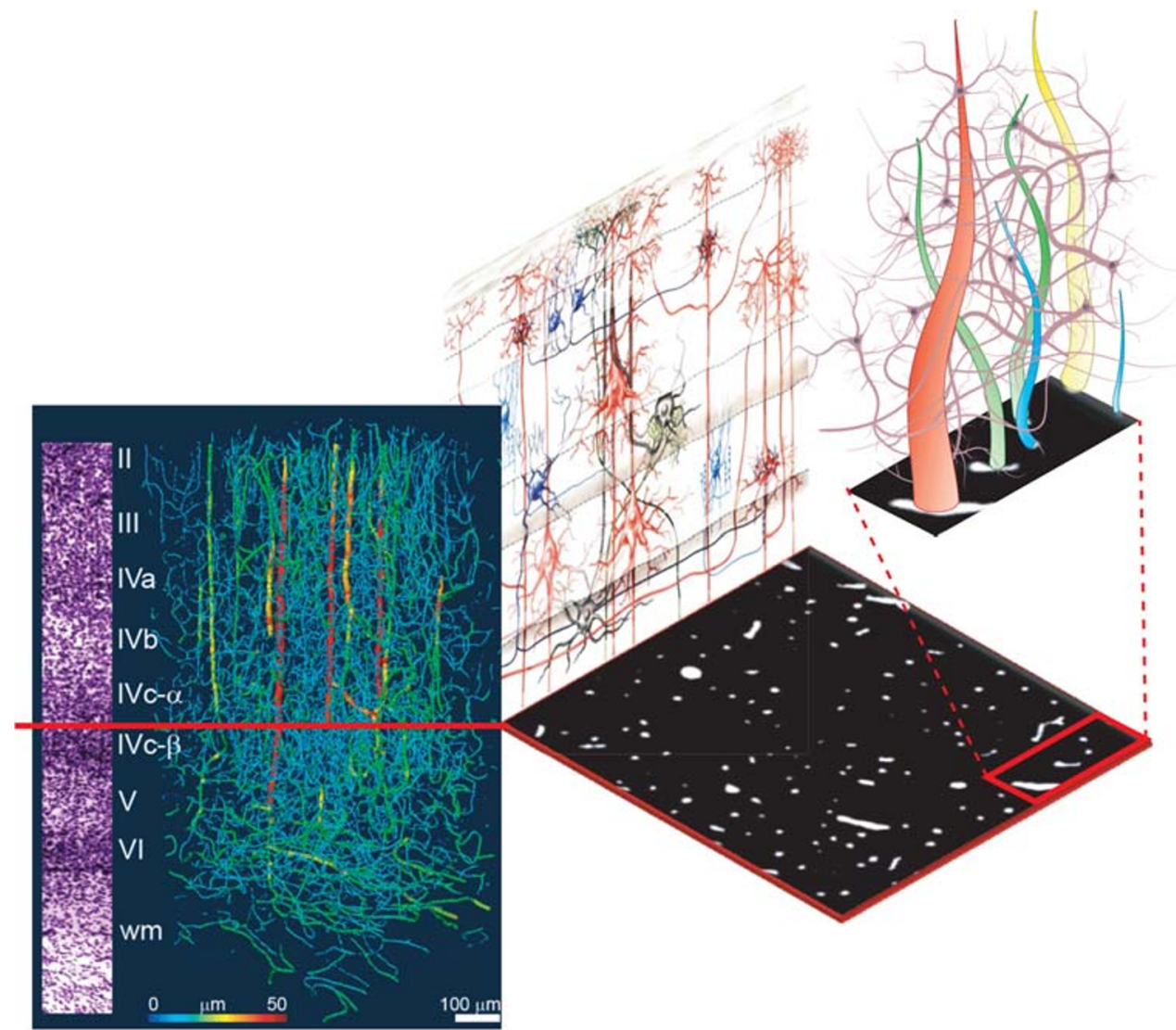

Fig. 6 Neural and vascular contents of a voxel. The left panel displays the relative density of vessels in the visual cortex of monkeys. The tissue is perfused with barium sulfate and imaged with synchrotron-based X-ray microtomography in order to display the dense vascular mesh (courtesy of B. Weber, MPI for Biological Cybernetics). At the top, the cortical surface without pial vessels is shown, and at the bottom, the white matter (wm) is shown. On the left side of the panel, a Nissl slice displaying the neural density from layers II through the wm is shown. The vessels seem to be high in density in this three-dimensional representation; however, in actuality, the density is less than $3 \%$ as displayed on the right by the white spots that represent the cross-sections of the vessels. The average distance between the small vessels is about $50 \mathrm{~mm}$, which is approximately the

movement $[126,127]$ for extended imaging times. These unique advantages and the wide availability of MRI scanners have led to a growing interest in ${ }^{17} \mathrm{O}$-based translational research [128-135].

Unlike ${ }^{15} \mathrm{O}$-PET that detects radioactivity from all ${ }^{15} \mathrm{O}$-labeled species, ${ }^{17} \mathrm{O}-\mathrm{MRI}$ measures metabolically generated ${ }^{17} \mathrm{O}$-water only. This property dramatically simplifies signal modeling to provide direct measurement of $\mathrm{CMRO}_{2}$ and $\mathrm{CBF}$. In addition, $\mathrm{CBF}$ can also be quantified from the washout kinetics of ${ }^{17} \mathrm{O}$-water $[130,136]$. Subsequently, OEF can be calculated as Eq. (6) (Fig. 2).

A middle-cerebral artery occlusion (MCAO) mouse model studied with ${ }^{17} \mathrm{O}-\mathrm{MRI}$ showed (Fig. 8) a decrease of mean $\mathrm{CMRO}_{2}$ from $2.44 \pm 0.29$ in the contralateral region to 1.66 $\pm 0.29 \mu \mathrm{mol} / \mathrm{g} / \mathrm{min}$ in the MCAO-affected region [130]. Accompanying this decrease in $\mathrm{CMRO}_{2}, \mathrm{OEF}$ increased from distance that oxygen molecules travel by diffusion within the limited transit time of the blood. A dense population of neurons, synapses, and glial cells occupy the intervascular space. A hypothetical distribution of these vascular and neural elements is depicted in the image at the top right by the small section in the red rectangle. The images above the rectangle display some of the typical neuronal types and their processes. For example, the large pyramidal cell is exhibited by the red, the inhibitory basket cells by the dark blue, the chandelier inhibitory neurons by the light blue, and stellate cells by the gray. Reprinted by permission from Nikos [37] (What we can do and what we cannot do with fMRI. Nature 453:869-878. Logothetis, Copyright (2008))

$0.35 \pm 0.07$ to $0.49 \pm 0.19$. This study provided compelling evidence that ${ }^{17} \mathrm{O}$-MRI can yield similar measurements of metabolic parameters as ${ }^{15} \mathrm{O}$-PET [122]. Yet, ${ }^{17} \mathrm{O}$-MRI suffers from the low sensitivity of ${ }^{17} \mathrm{O}$ in detection of $\mathrm{H}_{2}{ }^{17} \mathrm{O}$, because of the low gyromagnetic ratio and the extremely short $\mathrm{T}_{2}$ relaxation time $(<5 \mathrm{~ms})$ [137]. Even with a large number of signal averages to gain adequate signal-to-noise ratio, current ${ }^{17} \mathrm{O}-\mathrm{MRI}$ spatial resolution is insufficient to furnish adequate temporal resolution to capture $\mathrm{H}_{2}{ }^{17} \mathrm{O}$ generation and washout kinetics, thereby a necessity of ultrahigh field scanners (11.7 and $16.4 \mathrm{~T}$ ) to image cerebral metabolism in mouse brain with a sufficient resolution has delayed $[130,133,138]$ the routine availability and application of ${ }^{17} \mathrm{O}$-MRI.

More sophisticated image reconstruction methods that combine proton $\left({ }^{1} \mathrm{H}\right)$ MRI with ${ }^{17} \mathrm{O}-\mathrm{MRI}$ have been developed to improve the image quality and have shown feasibility 
a

$\circ$

-

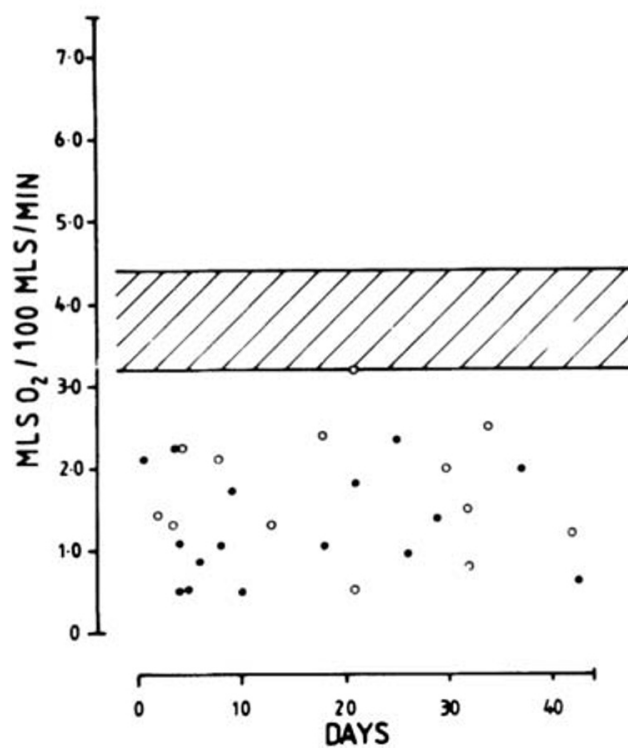

Fig. $7 \mathrm{rCMRO}_{2}$ of the infarcted area. Absolute (A) and relative (B) $\mathrm{rCMRO}_{2}$ at the center of the infarcted area. Relative $\mathrm{rCMRO}_{2}$ was calculated as a percent of the value in the symmetrical regions of interest in the contralateral cerebral hemispheres. The $x$-axis indicates the time of the PET scan in relation to the onset of stroke symptoms. Patients were divided into "good" (open circles) and "poor" (filled circles) outcome groups according to their clinical evolution. The shaded area in (A) indicates the mean $\mathrm{rCMRO}_{2}$ for the normal elderly population $\pm 1 \mathrm{SD}$. The lines in (B) interconnecting different studies

of performing ${ }^{17} \mathrm{O}$-MRI studies for quantifying $\mathrm{CMRO}_{2}$ at $3 \mathrm{~T}$ $[139,140]$. However, their spatial resolution may not be adequate to differentiate penumbra from infarct core. Another limitation for ${ }^{17} \mathrm{O}-\mathrm{MRI}$ is the relatively high cost of ${ }^{17} \mathrm{O}$-oxygen gas comparable to cyclotron-generated ${ }^{15} \mathrm{O}$-oxygen gas [137]. However, this limitation is largely market driven. As important ${ }^{17} \mathrm{O}$-MRI applications continue to emerge, the cost of ${ }^{17} \mathrm{O}$-oxygen gas can be significantly reduced when manufacturing volume rises to meet increased demand.

\section{Proton-Based MRI of Oxygen Metabolism}

Several proton $\left({ }^{1} \mathrm{H}\right)$-based MRI methods have been developed for evaluating oxygen metabolism. These methods take advantage of a phenomenon widely known as the BOLD contrast [16], which states that the $T_{2}$ and $T_{2}{ }^{*}$ relaxation is modulated by the deoxyhemoglobin concentration such that an increase in deoxyhemoglobin concentration leads to $\mathrm{T}_{2}$ and $\mathrm{T}_{2}{ }^{*}$ shortening. The $\mathrm{T}_{2}$-based methods such as $\mathrm{T}_{2}$-relaxation-under-spintagging were developed to directly quantify blood oxygenation in MR-visible vessels [141, 142]. Global OEF can be calculated from the difference of arterial and venous blood oxygenation in carotid artery and jugular vein [143-145]. Similarly, b

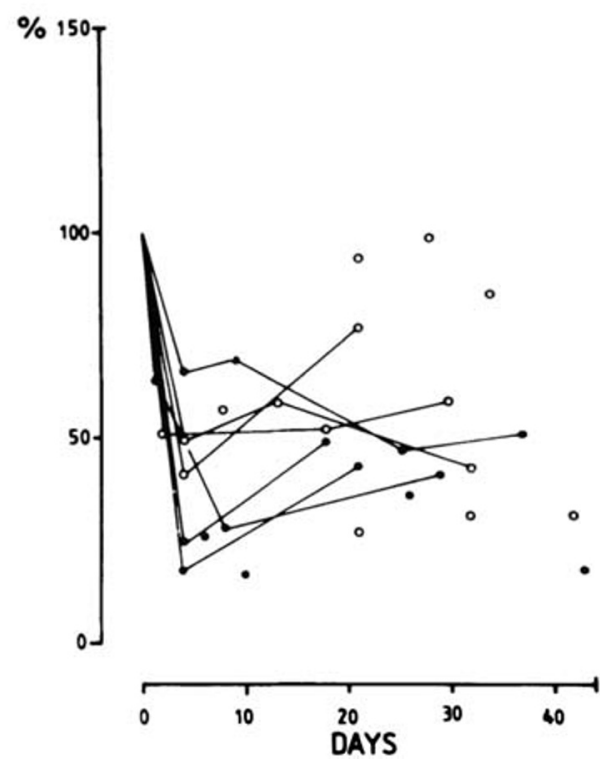

indicate individual patients who had follow-up PET scans. In the first days after a stroke, 6 of the 9 patients with a poor clinical outcome had an $\mathrm{rCMRO}_{2}$ below $1.25 \mathrm{ml} \mathrm{O}_{2} / 100 \mathrm{ml} / \mathrm{min}$ (A). (B) All the patients with a poor final outcome have an $\mathrm{rCMRO}_{2}$ that does not attain $50 \%$ of the value in the contralateral mirror locus. Lenzi et al. [116] (Cerebral oxygen metabolism and blood flow in human cerebral ischemic infarction. $J$ Cereb Blood Flow Metab 2:321-335. Copyright 1982, by Sage Publications. Reprinted with permission from Sage Publications, Ltd)

susceptometry-based oximetry (SBO) methods measure blood oxygenation from the phase shift caused by susceptibility changes induced by deoxyhemoglobin. By combining $\mathrm{T}_{2}-$ based or SBO methods with flow quantification, global $\mathrm{CMRO}_{2}$ can be calculated [146-150]. However, because these methods can only provide blood oxygenation measures in MRI visible vessels, they too are unable to provide blood oxygenation at a tissue level, essential for measuring regional changes in oxygen metabolism in post-stroke patients [151]. In contrast to $\mathrm{T}_{2}$-based and $\mathrm{SBO}$ methods, $\mathrm{T}_{2}{ }^{*}$ - and $\mathrm{T}_{2}{ }^{\prime}$-based methods such as quantitative BOLD and the asymmetric spin-echo methods are capable of quantifying blood oxygenation at a regional tissue level [152]. Compared to ${ }^{17} \mathrm{O}-\mathrm{MRI},{ }^{1} \mathrm{H}$-based MRI methods allow the quantification of metabolic activity in the brain with high spatial resolution. These methods calculate tissue oxygenation from measured $\mathrm{T}_{2}{ }^{*}$ or $\mathrm{T}_{2}{ }^{\prime}$ changes, assuming that intracranial vessels are randomly oriented with respect to the mail magnetic field. Although the assumption needs further examination and other factors that may impact susceptibility changes need to be fully characterized, these ${ }^{1} \mathrm{H}$-based methods can provide high spatial resolution even at a low field strength. Further, they do not require additional hardware of an $\mathrm{X}$-nuclei channel that is needed in ${ }^{17} \mathrm{O}$-MRI. Hence, these 
A

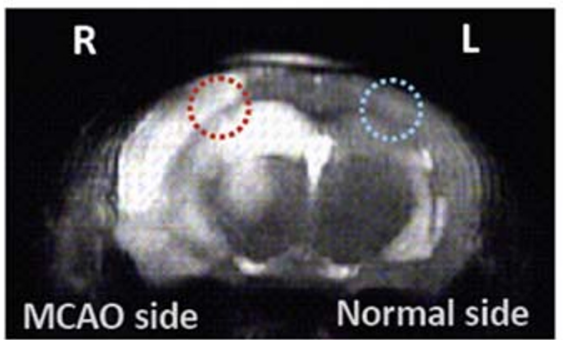

B

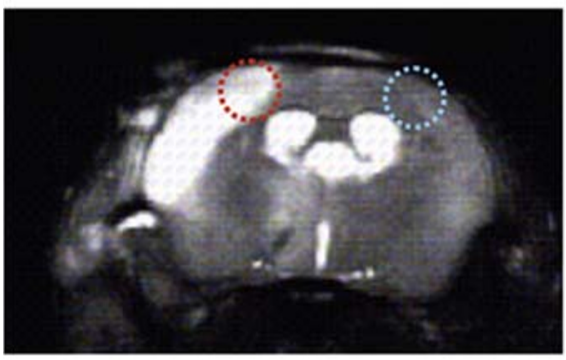

C

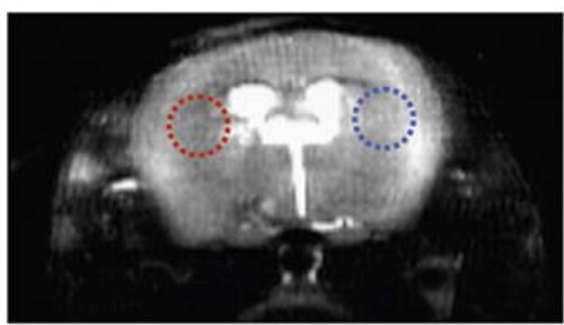

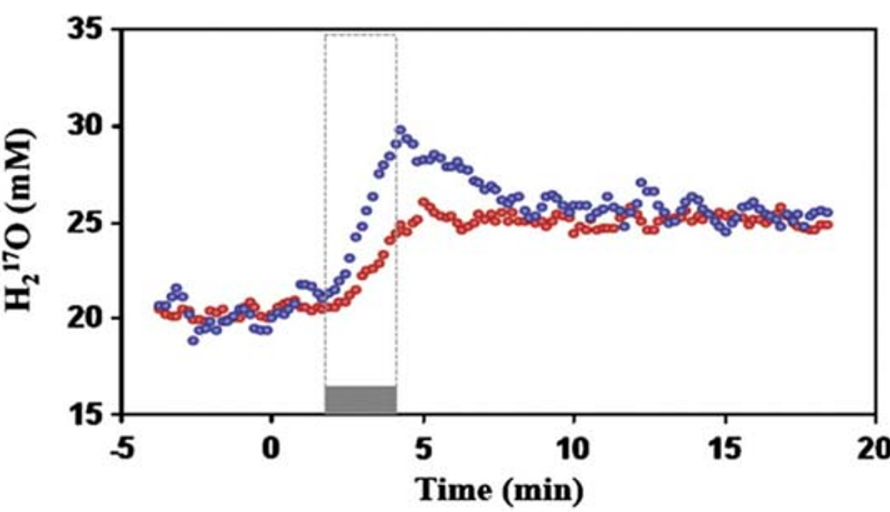
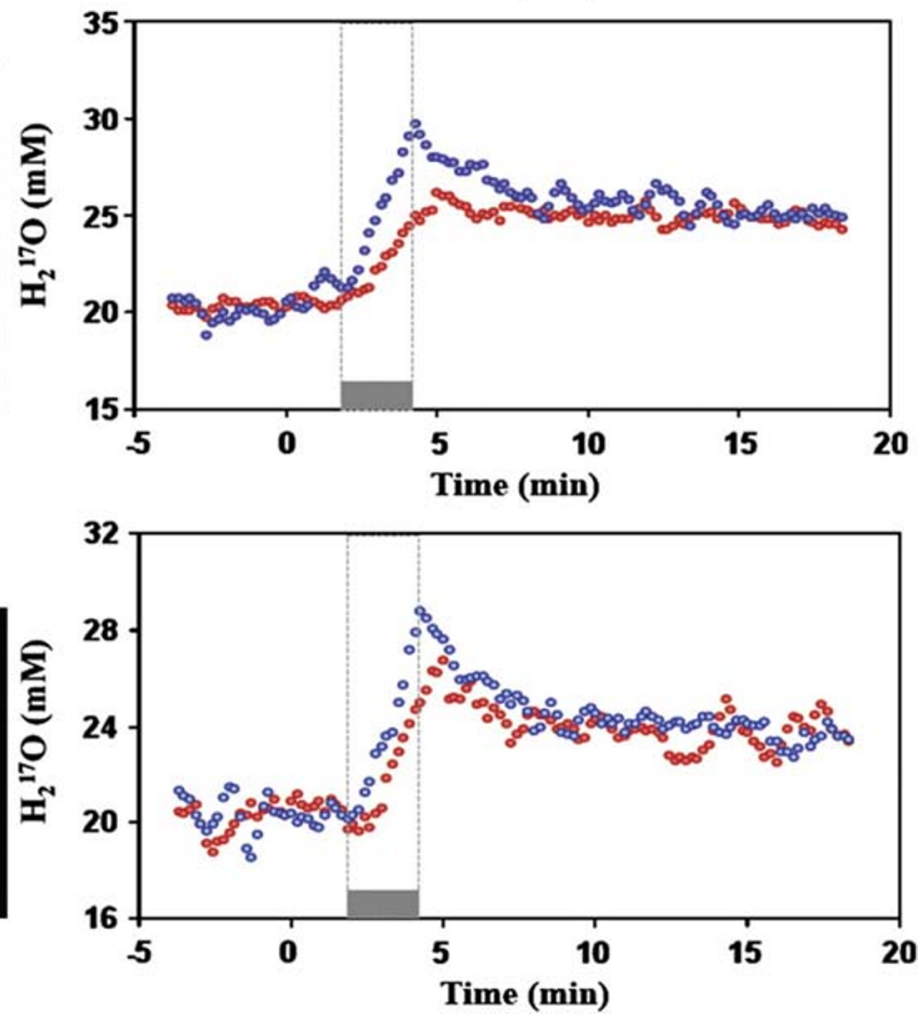

Fig. $8 \mathrm{CMRO}_{2}$ and $\mathrm{CBF}$ measurements in MCAO mouse. Comparison of $\mathrm{CMRO}_{2}$ and $\mathrm{CBF}$ measurements between the ${ }^{17} \mathrm{O}$-MRI voxels located in the MCAO-affected region (red circles) and the voxels located in the contralateral hemisphere of the same mouse brain (blue circles). (A, B) The anatomic images, selected voxels, and their corresponding dynamic ${ }^{17} \mathrm{O}$ signal changes before, during, and after a 2.5 -min inhalation of ${ }^{17} \mathrm{O}$ oxygen gas from 2 image slices in the same MCAO mouse. In the $\mathrm{MCAO}$-affected region, the slope of the ${ }^{17} \mathrm{O}$ signal increase during the

techniques are readily translatable to large-scale clinical investigations.

\section{Allied Molecular Probes as Metabolic Markers}

MRI with its incisive resolution $(\sim 100 \mu \mathrm{m})$ in high field scanners has made possible the use of functional dyes coupled with neuronal activity through technology surrounding metal ions, inhalation phase was substantially smaller and the rate of signal decay in the post-inhalation phase was also significantly reduced, indicating a large decrease in both $\mathrm{CMRO}_{2}$ and CBF. (C) Similar results from a different mouse brain. Reprinted from Zhu et al. [130] (Simultaneous and noninvasive imaging of cerebral oxygen metabolic rate, blood flow and oxygen extraction fraction in stroke mice. Neuroimage 64:437-447. Copyright (2013), with permission from Elsevier)

$\mathrm{pH}$, and neurotransmitter(s), as well as gene and protein expression [36].

Calcium-dependent MRI has witnessed the development of several relaxation-based contrast agents (Gd, manganese, and superparamagnetic iron oxide) undergoing scrutiny for an ease of delivery and preclinical application [153-156]. Similarly, ${ }^{13} \mathrm{C}$-labeled pyruvate and its kinetics during metabolism to lactate and alanine were found to be traceable but represent several hurdles (e.g., rapid decay and continuous 
supply) before realistic functional imaging value can be achieved [157]. A noteworthy development includes the detection of glutamate as a biomarker with chemical exchange saturation transfer MRI as opposed to traditional ${ }^{1} \mathrm{H}$ MRS [23, $158,159]$. Likewise, in vivo MRS monitoring of ${ }^{2} \mathrm{H}$-labeled substrates (glucose and $\mathrm{H}_{2} \mathrm{O}$ ) as well as metabolic intermediaries (glutamate, glutamine, or lactate) offers the opportunity to study the uncoupling of glycolysis and TCA cycle in complex pathophysiological states with improved spatiotemporal resolutions [160-162].

Otherwise, transition ions of zinc and copper undergo detectable alterations of their homeostasis during neuronal activity similar to calcium. Their $\mathrm{T}_{1}$ relaxation changes in vitro could potentially yield reliable ion-dependent MRI signal changes beyond cells incubated with the agent [163-165]. Also, iterations of Na-MRI though nascent hold promise to distinguish intracellular sodium maps in vivo between healthy and diseased brains. [166, 167]. And although $\mathrm{pH}$-sensitive probes are capable to exploit the acidification of the extracellular space from neuronal activity in vivo over a broad $\mathrm{T}_{2}$ relaxation [168-171], their clinical utility awaits optimization for a sensitivity of $\mathrm{pH} 7.2$ to 7.4 [172].

Of great interest are genetic contrast agents (metalloproteins) such as ferritin which once transfected into target cells through a vector is made superparamagnetic via endogenous iron sequestration [173-175]. Using a reporter gene that encodes a lysine-rich protein might distinguish viable from nonviable cells and enable a constant endogenous level of expression [176].

These modalities can be detected in multiple tissue types with zero potential adverse effects, can be switched on and off selectively at the exchangeable proton resonance frequency, and possess numerous biomedical applications, such as visualizing preclinical therapeutic gene delivery [176, 177].

\section{Neurotherapeutic Perspective}

The acutely injured brain is particularly sensitive to episodes of glycemic fluctuations. Clinical manifestations ranging from confusion to seizure correlate with regional differences in brain glucose metabolism [178]. Spreading depression in stroke, SAH, and TBI is known to perturb cortical glucose metabolism, which in turn is associated with axonal degeneration. CNS axonopathy and peripheral neuropathy are linked to disrupted lactate transportation and oxidative phosphorylation, respectively [179]. Likewise, MS and anti-NMDAR encephalitis exhibit characteristic [18F] FDG-PET abnormalities [179]. Similar associations portend worse prognosis after TBI or perhaps other states of elevated ICP [180-184]. Conversely, a normalization in cerebral energetics accompanies recovery [179]. Lactate is recognized as the preferred fuel in CNS metabolism. Consequently, hypertonic lactate has emerged as a potential therapeutic target to re-establish a favorable cerebral metabolic state following TBI [180]. Differential therapeutic targeting of monocarboxyate transporter isoforms in malignant CNS tumors is another promising approach [185].

The availability of lactate is also neuroprotective in the reoxygenation phase after cerebral stroke [186]. Elsewhere, downregulation of monocarboxyate transporter at the BBB and preferential cytosolic accumulation of lactate suggest a protective mechanism against treatment-resistant epilepsy [186]. Of special mention is the landmark paper by Malkov et al. [187] which purports the exploitation of the $N$-methyl-Daspartate and nicotinamide adenine dinucleotide phosphate oxidase interaction in the quest to address treatment refractory epilepsy.

Similar supplementation of ketones such as $\beta$ hydroxybutyrate is another lucrative target for modulation of brain metabolism in acute injury [188-191]. Metabolic imaging then becomes ideal to investigate the putative benefits of the aforesaid approaches and vehicles such as dimethyl sulfoxide which facilitate drug delivery across the BBB, but also possess potentially far-reaching metabolic properties [187, 192]. Finally, our struggle to measure neuronal reorganization and recovery in brain injury can be addressed by the BOLD signal paving way for a proreparative, neuronal supportive phenotype of the astrocyte [193-195].

\section{Conclusion}

The introduction of metabolic imaging allows readily translatable neuroscience and ushers an exciting new era of precision medicine. This approach promises the resolution at anatomic (spatial) as well as temporal (pathophysiological) levels of disease organization. Its application to cellular, subcellular, molecular, and functional (synaptic) neuroenergetics will enable the development of novel therapeutic targets and specify outcome measures [188-195].

Metabolic MRI satisfies desirable clinical and economic characteristics for diagnostic tests, i.e., noninvasive, nonradioactive, with the least possible deleterious effects, with high positive and negative predictive value, and amenable to upscaling (eventual low cost and readily generalizable). Beyond slowly progressive neurodegenerative, neurobehavioral, and neuro-oncological states, MRI now stands to inform the acute management of TBI, tumor (edema and resection), ischemia, and epilepsy.

Although satisfactory in the previously suggested criteria, metabolic MRI's true potential remains to be fulfilled. Its temporal resolution requires repeated sampling throughout time and demands supplementation with technologies such as continuous EEG monitoring and the fabled but ever quintessential serial bedside neurological examination. In addition, 
enhanced spatial resolution demands further development of sampling strategies yet ensure the clinical feasibility of 3-T magnetic fields. Above detractions notwithstanding, rapid technological improvements render reasonable expectation for immediate translation to human work (e.g., ${ }^{17} \mathrm{O}$ ) [196-198].

Continued insights regarding the metabolic processes at the cellular CNS level argue for the development and implementation of diagnostic technology which observes the spatial and temporal heterogeneity of neuroenergetics. Current limitations pertaining the assessment of inherent fundamental neurovascular coupling mechanisms prohibit an accurate delineation of cell-specific processes. Ongoing approaches through glucose, amino acids (glutamate, GABA, glycine), nucleosides, neurotransmitters (VIP or NA), and intracellular signaling moieties (calcium, sodium, cyclic adenosine monophosphate, and inositol triphosphate), which require carrier-mediated transport through the BBB [199], represent lucrative substrates for mapping via structurally analog reporter molecules, e.g., PET (FDG for glucose) [200, 201]. Conversely, reporter probes capable of targeting signature receptors, enzymes, and cytokines present a new frontier to study specific molecular and cellular events of metabolism [202]. Ideal diagnostic and therapeutic targets would express at optimal levels in the biological process of interest and would bind with a complementary ligand (e.g., receptor agonists, antibodies, or peptides) to allow detection. A need for molecular target sensitive MR contrast agent would then exist. Already proven for glutamate-based chemical exchange saturation transfer MRI and cytosolic calcium, other MRI methods for assessing metabolic activity could involve hyperpolarized C13, P31 chemical shift imaging and OEF by susceptibility imaging. Additional impetus for functional imaging would come in the form of contrast agents derived from transition metal ions and $\mathrm{pH}$, as well as gene and protein expression [36].

In summary, we share the general optimism that metabolic imaging lends to biochemical, biologic, diagnostic, or therapeutic applications in neurocritical care. MR imaging offers a more faithful estimation of cellular level neuroenergetic compromise. Its visibility for metabolic end products such as $\mathrm{H}_{2} \mathrm{O}$ and ATP anticipates the estimation of a true penumbra from detailed maps such as $\mathrm{CMRO}_{2}$. Such molecular level penumbral detection currently evades CTP-mediated perfusion maps. Similarly, for the logistically cumbersome PET, if inquiry is to shift from purely oxidative metabolism to cell- and expression-specific metabolic targets, there would also exist a need for novel radiotracers. Finally, as important new tracers (e.g., ${ }^{17} \mathrm{O},{ }^{31} \mathrm{P},{ }^{23} \mathrm{Na}$ ) for MRI applications emerge, their implementation would achieve economic viability when supply meets demand. Noninvasive MRI-based metabolic imaging is approaching the temporal and spatial resolution that complements basic scientific and clinical studies $[8,26]$. Although most promising, future directions shall confirm current preclinical data on their sensitivity and specificity before translation to neurocritical care [196-198].

Acknowledgments This work was supported by National Institutes of Health funding: NIH NINDS RES512515 and NIH 5-R01-EB02370403EB023704.

\section{References}

1. Magistretti PJ, Allaman I. A cellular perspective on brain energy metabolism and functional imaging. Neuron. 2015;86(4):883901.

2. Herculano-Houzel S. Scaling of brain metabolism with a fixed energy budget per neuron: implications for neuronal activity, plasticity and evolution. PLoS One 2011;6(3):e17514.

3. Goyal MS, Hawrylycz M, Miller JA, Snyder AZ, Raichle ME. Aerobic glycolysis in the human brain is associated with development and neotenous gene expression. Cell Metab 2014;19(1):4957.

4. Bauernfeind AL, Barks SK, Duka T, Grossman LI, Hof PR, Sherwood CC. Aerobic glycolysis in the primate brain: reconsidering the implications for growth and maintenance. Brain Struct Funct 2014;219(4):1149-67.

5. Bélanger M, Allaman I, Magistretti PJ. Brain energy metabolism: focus on astrocyte-neuron metabolic cooperation. Cell Metab 2011;14(6):724-38.

6. Roy CS, Sherrington CS. On the regulation of the blood-supply of the brain. J Physiol 1890;11(1-2):85-158 17.

7. Attwell D, Buchan AM, Charpak S, Lauritzen M, Macvicar BA, Newman EA. Glial and neuronal control of brain blood flow. Nature 2010;468(7321):232-243.

8. Cauli B, Hamel E. Revisiting the role of neurons in neurovascular coupling. Front Neuroenerg 2010;2:9.

9. Filosa JA, Iddings JA. Astrocyte regulation of cerebral vascular tone. Am J Physiol Heart Circ Physiol 2013;305(5):H609-H619.

10. Petzold GC, Murthy VN. Role of astrocytes in neurovascular coupling. Neuron. 2011;71(5):782-\&97.

11. Hillman EM. Coupling mechanism and significance of the BOLD signal: a status report. Annu Rev Neurosci 2014;37:161-181.

12. Kleinfeld D, Blinder P, Drew PJ, et al. A guide to delineate the logic of neurovascular signaling in the brain. Front Neuroenerg 2011;3:1.

13. Logothetis NK, Pauls J, Augath M, Trinath T, Oeltermann A. Neurophysiological investigation of the basis of the fMRI signal. Nature. 2001;412(6843):150.

14. Raichle ME. Positron emission tomography. Annu Rev Neurosci 1983;6(1):249-267.

15. Raichle ME. Behind the scenes of functional brain imaging: a historical and physiological perspective. Proc Natl Acad Sci 1998;95(3):765-772.

16. Ogawa S, Lee T-M, Kay AR, Tank DW Brain magnetic resonance imaging with contrast dependent on blood oxygenation. Proc Natl Acad Sci 1990;87(24):9868-9872.

17. Fox PT, Raichle ME, Mintun MA, Dence C. Nonoxidative glucose consumption during focal physiologic neural activity. Science (New York, NY). 1988;241(4864):462-464.

18. Fox PT, Raichle ME. Focal physiological uncoupling of cerebral blood flow and oxidative metabolism during somatosensory stimulation in human subjects. Proc Natl Acad Sci U S A 1986;83(4): 1140-1144.

19. Sappey-Marinier D, Calabrese G, Fein G, Hugg JW, Biggins C, Weiner MW. Effect of photic stimulation on human visual cortex 
lactate and phosphates using $1 \mathrm{H}$ and $31 \mathrm{P}$ magnetic resonance spectroscopy. J Cereb Blood Flow Metab 1992;12(4):584-592.

20. Prichard J, Rothman D, Novotny E, et al. Lactate rise detected by $1 \mathrm{H}$ NMR in human visual cortex during physiologic stimulation. Proc Natl Acad Sci U S A 1991;88(13):5829-5831.

21. Ogawa S, Tank DW, Menon R, et al. Intrinsic signal changes accompanying sensory stimulation: functional brain mapping with magnetic resonance imaging. Proc Natl Acad Sci U S A 1992;89(13):5951-5955.

22. Hyder $\mathrm{F}$ and Rothman DL. Advances in imaging brain metabolism. Annu Rev Biomed Eng 2017;19:485-515.

23. Duarte JM, Lei H, Mlynárik V, Gruetter R. The neurochemical profile quantified by in vivo $1 \mathrm{H}$ NMR spectroscopy. Neuroimage. 2012;61(2):342-62.

24. Shulman RG, Rothman DL. 13C NMR of intermediary metabolism: implications for systemic physiology. Annu Rev Physiol 2001;63(1):15-48.

25. Bonvento G, Valette J, Flament J, Mochel F, Brouillet E. Imaging and spectroscopic approaches to probe brain energy metabolism dysregulation in neurodegenerative diseases. J Cereb Blood Flow Metab 2017;37(6):1927-1943.

26. Shulman RG, Hyder F, Rothman DL. Lactate efflux and the neuroenergetic basis of brain function. NMR Biomed 2001;14(7-8):389-396.

27. Forsén S, Hoffman RA. Study of moderately rapid chemical exchange reactions by means of nuclear magnetic double resonance. J Chem Phys 1963;39(11):2892-2901.

28. Cahoy JD, Emery B, Kaushal A, et al. A transcriptome database for astrocytes, neurons, and oligodendrocytes: a new resource for understanding brain development and function. J Neurosci 2008;28(1):264-278

29. Lovatt D, Sonnewald U, Waagepetersen HS, et al. The transcriptome and metabolic gene signature of protoplasmic astrocytes in the adult murine cortex. J Neurosci 2007;27(45):1225512266.

30. Zhang Y, Chen K, Sloan SA, Bennett ML, et al. An RNAsequencing transcriptome and splicing database of glia, neurons, and vascular cells of the cerebral cortex. J Neurosci 2014;34(36): 11929-11947.

31. Barros LF, San Martin A, Sotelo-Hitschfeld T, et al. Small is fast: astrocytic glucose and lactate metabolism at cellular resolution. Front Cell Neurosci 2013;7:27.

32. Chuquet J, Quilichini P, Nimchinsky EA, Buzsaki G. Predominant enhancement of glucose uptake in astrocytes versus neurons during activation of the somatosensory cortex. J Neurosci 2010;30(45):15298-15303.

33. Jakoby P, Schmidt E, Ruminot I, Gutierrez R, Barros LF, Deitmer JW. Higher transport and metabolism of glucose in astrocytes compared with neurons: a multiphoton study of hippocampal and cerebellar tissue slices. Cereb Cortex 2014;24(1):222-231.

34. Bartelle BB, Barandov A, Jasanoff A. Molecular fMRI. J Neurosci 2016;36(15):4139-4148.

35. Constable RT. Challenges in fMRI and its limitations. Functional MRI. Springer; 2006. p. 75-98.

36. Jasanoff A. MRI contrast agents for functional molecular imaging of brain activity. Curr Opin Neurobiol 2007;17(5):593-600.

37. Logothetis NK. What we can do and what we cannot do with fMRI. Nature 2008;453(7197):869-878.

38. Glover GH. Overview of functional magnetic resonance imaging. Neurosurg Clin N Am 2011;22(2):133-139, vii.

39. Rose J, Valtonen S, Jennett B. Avoidable factors contributing to death after head injury. Br Med J 1977;2(6087):615-618.

40. Miller JD, Piper IR, Jones PA. Integrated multimodality monitoring in the neurosurgical intensive care unit. Neurosurg Clin N Am 1994;5(4):661-670
41. Le Roux P, Menon DK, Citerio G, et al. Consensus summary statement of the international multidisciplinary consensus conference on multimodality monitoring in neurocritical care. Neurocrit Care 2014;21(2):1-26.

42. Torbey MT, Bosel J, Rhoney DH, et al. Evidence-based guidelines for the management of large hemispheric infarction : a statement for health care professionals from the Neurocritical Care Society and the German Society for Neuro-intensive Care and Emergency Medicine. Neurocrit Care 2015;22(1):146-164.

43. Purkayastha S, Sorond F. Transcranial Doppler ultrasound: technique and application. Semin Neurol 2012;32(4):411-420.

44. Willie CK, Tzeng YC, Fisher JA, Ainslie PN. Integrative regulation of human brain blood flow. J Physiol 2014;592(5):841-859.

45. Brugniaux JV, Hodges AN, Hanly PJ, Poulin MJ. Cerebrovascular responses to altitude. Respir Physiol Neurobiol 2007;158(2-3): 212-223.

46. Dunn JF, Wu Y, Zhao Z, Srinivasan S, Natah SS. Training the brain to survive stroke. PLoS One 2012;7(9):e45108.

47. Hamer J, Wiedemann K, Berlet H, Weinhardt F, Hoyer S. Cerebral glucose and energy metabolism, cerebral oxygen consumption, and blood flow in arterial hypoxaemia. Acta Neurochir 1978;44(3-4):151-160

48. Spencer JA, Ferraro F, Roussakis E, et al. Direct measurement of local oxygen concentration in the bone marrow of live animals. Nature. 2014;508(7495):269-273.

49. Malte H, Lykkeboe G. The Bohr/Haldane effect: a model-based uncovering of the full extent of its impact on $\mathrm{O} 2$ delivery to and CO2 removal from tissues. J Appl Physiol (1985). 2018;125(3): 916-922.

50. Peacock AJ. ABC of oxygen: oxygen at high altitude. BMJ. 1998;317(7165):1063-1066.

51. Ellsworth ML, Pittman RN. Arterioles supply oxygen to capillaries by diffusion as well as by convection. Am J Phys 1990;258(4 Pt 2):H1240-H1243.

52. Bodmer SI, Balestra GM, Harms FA, et al. Microvascular and mitochondrial $\mathrm{PO}(2)$ simultaneously measured by oxygendependent delayed luminescence. J Biophotonics 2012;5(2):140151.

53. Mik EG. Special article: measuring mitochondrial oxygen tension: from basic principles to application in humans. Anesth Analg 2013;117(4):834-846.

54. Meixensberger J, Dings J, Kuhnigk H, Roosen K. Studies of tissue PO2 in normal and pathological human brain cortex. Acta Neurochir Suppl (Wien) 1993;59:58-63.

55. Hoffman WE, Charbel FT, Edelman G. Brain tissue oxygen, carbon dioxide, and $\mathrm{pH}$ in neurosurgical patients at risk for ischemia. Anesth Analg 1996;82(3):582-586.

56. Zacchetti L, Magnoni S, Di Corte F, Zanier ER, Stocchetti N. Accuracy of intracranial pressure monitoring: systematic review and meta-analysis. Crit Care 2015;19:420.

57. Raabe A, Totzauer R, Meyer O, Stockel R, Hohrein D, Schoche J Reliability of epidural pressure measurement in clinical practice: behavior of three modern sensors during simultaneous ipsilateral intraventricular or intraparenchymal pressure measurement. Neurosurgery. 1998;43(2):306-311.

58. Tavakoli S, Peitz G, Ares W, Hafeez S, Grandhi R. Complications of invasive intracranial pressure monitoring devices in neurocritical care. Neurosurg Focus 2017;43(5):E6.

59. Sinha S, Hudgins E, Schuster J, Balu R. Unraveling the complexities of invasive multimodality neuromonitoring. Neurosurg Focus 2017;43(5):E4

60. Ortiz-Prado E, Dunn JF, Vasconez J, Castillo D, Viscor G. Partial pressure of oxygen in the human body: a general review. Am J Blood Res 2019;9(1):1-14.

61. Stevens WJ. Multimodal monitoring: head injury management using SjvO2 and LICOX. J Neurosci Nurs 2004;36(6):332-339. 
62. Bouzat P, Marques-Vidal P, Zerlauth JB, et al. Accuracy of brain multimodal monitoring to detect cerebral hypoperfusion after traumatic brain injury*. Crit Care Med 2015;43(2):445-452.

63. Kennedy RT. Emerging trends in in vivo neurochemical monitoring by microdialysis. Curr Opin Chem Biol 2013;17(5):860-867.

64. Thelin EP, Carpenter KL, Hutchinson PJ, Helmy A. Microdialysis monitoring in clinical traumatic brain injury and its role in neuroprotective drug development. AAPS J 2017;19(2):367-376.

65. Ngernsutivorakul T, White TS, Kennedy RT. Microfabricated probes for studying brain chemistry: a review. Chemphyschem. 2018;19(10):1128-1142.

66. Lee WH, Ngernsutivorakul T, Mabrouk OS, et al. Microfabrication and in vivo performance of a microdialysis probe with embedded membrane. Anal Chem 2016;88(2):12301237.

67. Hinzman JM, Gibson JL, Tackla RD, et al. Real-time monitoring of extracellular adenosine using enzyme-linked microelectrode arrays. Biosens Bioelectron 2015;74:512-517.

68. Jobsis FF. Noninvasive, infrared monitoring of cerebral and myocardial oxygen sufficiency and circulatory parameters. Science (New York, NY). 1977;198(4323):1264-1267.

69. Boas DA, Campbell LE, Yodh AG. Scattering and imaging with diffusing temporal field correlations. Phys Rev Lett 1995;75(9): $1855-1858$.

70. Krakauskaite S, Petkus V, Bartusis L, et al. Accuracy, precision, sensitivity, and specificity of noninvasive ICP absolute value measurements. Acta Neurochir Suppl 2016;122:317-321.

71. Robba C, Cardim D, Tajsic T, et al. Non-invasive intracranial pressure assessment in brain injured patients using ultrasoundbased methods. Acta Neurochir Suppl 2018;126:69-73.

72. Zhang X, Medow JE, Iskandar BJ, et al. Invasive and noninvasive means of measuring intracranial pressure: a review. Physiol Meas 2017;38(8):R143-R182.

73. Cloostermans MC, van Meulen FB, Eertman CJ, Hom HW, van Putten MJ. Continuous electroencephalography monitoring for early prediction of neurological outcome in postanoxic patients after cardiac arrest: a prospective cohort study. Crit Care Med 2012;40(10):2867-2875.

74. Hamberger A, Hydén H. Inverse enzymatic changes in neurons and glia during increased function and hypoxia. J Cell Biol 1963;16(3):521-525.

75. Hydén H, Lange PW. A kinetic study of the neuron-glia relationship. J Cell Biol 1962;13(2):233-237.

76. Tabata H. Diverse subtypes of astrocytes and their development during corticogenesis. Front Neurosci 2015;9:114.

77. Harris JJ, Jolivet R, Attwell D. Synaptic energy use and supply. Neuron. 2012;75(5):762-777

78. Rogatzki MJ, Ferguson BS, Goodwin ML, Gladden LB. Lactate is always the end product of glycolysis. Front Neurosci 2015;9:22.

79. Vaishnavi SN, Vlassenko AG, Rundle MM, Snyder AZ, Mintun MA, Raichle ME. Regional aerobic glycolysis in the human brain. Proc Natl Acad Sci 2010;107(41):17757-17762.

80. Bouzier-Sore AK, Voisin P, Bouchaud V, Bezancon E, Franconi JM, Pellerin L. Competition between glucose and lactate as oxidative energy substrates in both neurons and astrocytes: a comparative NMR study. Eur J Neurosci 2006;24(6):1687-1694.

81. Selak I, Skaper SD, Varon S. Pyruvate participation in the low molecular weight trophic activity for central nervous system neurons in glia-conditioned media. J Neurosci 1985;5(1):23-28.

82. Shulman RG, Hyder F, Rothman DL. Cerebral energetics and the glycogen shunt: neurochemical basis of functional imaging. Proc Natl Acad Sci 2001;98(11):6417-6422.

83. Katz LC, Shatz CJ. Synaptic activity and the construction of cortical circuits. Science (New York, NY). 1996;274(5290):11331138 .
84. Pavlides S, Tsirigos A, Vera I, et al. Transcriptional evidence for the "reverse Warburg effect" in human breast cancer tumor stroma and metastasis: similarities with oxidative stress, inflammation, Alzheimer's disease, and "neuron-glia metabolic coupling". Aging (Albany NY). 2010;2(4):185.

85. Warburg O. On the origin of cancer cells. Science (New York, NY). 1956;123(3191):309-314.

86. Bélanger M, Yang J, Petit J-M, Laroche T, Magistretti PJ, Allaman I. Role of the glyoxalase system in astrocyte-mediated neuroprotection. J Neurosci 2011;31(50):18338-18352.

87. Herrero-Mendez A, Almeida A, Fernández E, Maestre C, Moncada S, Bolaños JP. The bioenergetic and antioxidant status of neurons is controlled by continuous degradation of a key glycolytic enzyme by APC/C-Cdh1. Nat Cell Biol 2009;11(6):747.

88. Bennett CM, Miller MB. How reliable are the results from functional magnetic resonance imaging? Ann N Y Acad Sci 2010;1191:133-155.

89. Bennett CM, Miller MB, Wolford GL. Neural correlates of interspecies perspective taking in the post-mortem Atlantic salmon: an argument for multiple comparisons correction. NeuroImage 2009;47:S125.

90. Astrup J, Siesjo BK, Symon L. Thresholds in cerebral ischemiathe ischemic penumbra. Stroke. 1981;12(6):723-725.

91. Trojaborg W, Boysen G. Relation between EEG, regional cerebral blood flow and internal carotid artery pressure during carotid endarterectomy. Electroencephalogr Clin Neurophysiol 1973;34(1): 61-69.

92. Sundt TM, Jr., Sharbrough FW, Anderson RE, Michenfelder JD. Cerebral blood flow measurements and electroencephalograms during carotid endarterectomy. 1974. J Neurosurg 2007;107(4): 887-897.

93. Astrup J, Symon L, Branston NM, Lassen NA. Cortical evoked potential and extracellular $\mathrm{K}+$ and $\mathrm{H}+$ at critical levels of brain ischemia. Stroke. 1977;8(1):51-57.

94. Salford LG, Plum F, Siesjo BK. Graded hypoxia-oligemia in rat brain. I. Biochemical alterations and their implications. Arch Neurol 1973;29(4):227-233.

95. Salford LG, Plum F, Brierley JB. Graded hypoxia-oligemia in rat brain. II. Neuropathological alterations and their implications. Arch Neurol 1973;29(4):234-238.

96. Dani KA, Warach S. Metabolic imaging of ischemic stroke: the present and future. AJNR Am J Neuroradiol 2014;35(6 Suppl): S37-S43

97. Campbell BC, Christensen S, Levi CR, et al. Comparison of computed tomography perfusion and magnetic resonance imaging perfusion-diffusion mismatch in ischemic stroke. Stroke. 2012;43(10):2648-2653.

98. Allmendinger AM, Tang ER, Lui YW, Spektor V. Imaging of stroke: part 1, perfusion CT-overview of imaging technique, interpretation pearls, and common pitfalls. AJR Am J Roentgenol 2012;198(1):52-62

99. Maurer I, Zierz S, Moller H. Evidence for a mitochondrial oxidative phosphorylation defect in brains from patients with schizophrenia. Schizophr Res 2001;48(1):125-136.

100. Wong-Riley M, Antuono P, Ho KC, et al. Cytochrome oxidase in Alzheimer's disease: biochemical, histochemical, and immunohistochemical analyses of the visual and other systems. Vis Res 1997;37(24):3593-3608

101. Maurer I, Zierz S, Moller HJ. A selective defect of cytochrome c oxidase is present in brain of Alzheimer disease patients. Neurobiol Aging 2000;21(3):455-462.

102. Frackowiak RS, Herold S, Petty RK, Morgan-Hughes JA. The cerebral metabolism of glucose and oxygen measured with positron tomography in patients with mitochondrial diseases. Brain. 1988;111 (Pt 5):1009-1024. 
103. Beal MF. Does impairment of energy metabolism result in excitotoxic neuronal death in neurodegenerative illnesses? Ann Neurol 1992;31(2):119-130.

104. Harrison RV, Harel N, Panesar J, Mount RJ. Blood capillary distribution correlates with hemodynamic-based functional imaging in cerebral cortex. Cereb Cortex 2002;12(3):225-233.

105. Chang FY, Xiao JX, Xie S, et al. Determination of oxygen extraction fraction using magnetic resonance imaging in canine models with internal carotid artery occlusion. Sci Rep 2016;6:30332.

106. An H, Ford AL, Chen Y, et al. Defining the ischemic penumbra using magnetic resonance oxygen metabolic index. Stroke. 2015;46(4):982-988.

107. Kim BJ, Kang HG, Kim HJ, et al. Magnetic resonance imaging in acute ischemic stroke treatment. J Stroke 2014;16(3):131-145.

108. Guadagno JV, Warburton EA, Jones PS, et al. How affected is oxygen metabolism in DWI lesions?: a combined acute stroke PET-MR study. Neurology. 2006;67(5):824-829.

109. Kidwell CS, Saver JL, Mattiello J, et al. Thrombolytic reversal of acute human cerebral ischemic injury shown by diffusion/ perfusion magnetic resonance imaging. Ann Neurol 2000;47(4): 462-469.

110. Nogueira RG, Jadhav AP, Haussen DC, et al. Thrombectomy 6 to 24 hours after stroke with a mismatch between deficit and infarct. N Engl J Med 2018;378(1):11-21.

111. Powers WJ, Rabinstein AA, Ackerson T, et al. Guidelines for the early management of patients with acute ischemic stroke: 2019 update to the 2018 guidelines for the early management of acute ischemic stroke: a guideline for healthcare professionals from the American Heart Association/American Stroke Association. Stroke. 2019;50(12):e344-e418.

112. Sobesky J. Refining the mismatch concept in acute stroke: lessons learned from PET and MRI. J Cereb Blood Flow Metab 2012;32(7):1416-1425.

113. Frackowiak RS, Lenzi GL, Jones T, Heather JD. Quantitative measurement of regional cerebral blood flow and oxygen metabolism in man using 150 and positron emission tomography: theory, procedure, and normal values. J Comput Assist Tomogr 1980;4(6):727-736

114. Mintun MA, Raichle ME, Martin WR, Herscovitch P. Brain oxygen utilization measured with $\mathrm{O}-15$ radiotracers and positron emission tomography. J Nucl Med 1984;25(2):177-187.

115. Baron JC, Bousser MG, Comar D, Soussaline F, Castaigne P. Noninvasive tomographic study of cerebral blood flow and oxygen metabolism in vivo. Potentials, limitations, and clinical applications in cerebral ischemic disorders. Eur Neurol 1981;20(3): 273-284.

116. Lenzi GL, Frackowiak RS, Jones T. Cerebral oxygen metabolism and blood flow in human cerebral ischemic infarction. J Cereb Blood Flow Metab 1982;2(3):321-335.

117. Marchal G, Beaudouin V, Rioux P, et al. Prolonged persistence of substantial volumes of potentially viable brain tissue after stroke: a correlative PET-CT study with voxel-based data analysis. Stroke. 1996;27(4):599-606

118. Marchal G, Serrati C, Rioux P, et al. PET imaging of cerebral perfusion and oxygen consumption in acute ischaemic stroke: relation to outcome. Lancet. 1993;341(8850):925-927.

119. del Zoppo GJ, Sharp FR, Heiss WD, Albers GW. Heterogeneity in the penumbra. J Cereb Blood Flow Metab 2011;31(9):1836-1851.

120. Baron JC, Rougemont D, Soussaline F, et al. Local interrelationships of cerebral oxygen consumption and glucose utilization in normal subjects and in ischemic stroke patients: a positron tomography study. J Cereb Blood Flow Metab 1984;4(2):140-149.

121. Marchal G, Benali K, Iglesias S, Viader F, Derlon JM, Baron JC. Voxel-based mapping of irreversible ischaemic damage with PET in acute stroke. Brain J Neurol 1999:122:2387-2400.
122. Heiss WD. Ischemic penumbra: evidence from functional imaging in man. J Cereb Blood Flow Metab 2000;20(9):1276-1293.

123. Arai T, Nakao S, Mori K, et al. Cerebral oxygen utilization analyzed by the use of oxygen-17 and its nuclear magnetic resonance. Biochem Biophys Res Commun 1990;169(1):153-158.

124. Arai T, Mori K, Nakao S, et al. In vivo oxygen-17 nuclear magnetic resonance for the estimation of cerebral blood flow and oxygen consumption. Biochem Biophys Res Commun 1991;179(2): 954-961.

125. Pekar J, Ligeti L, Ruttner Z, et al. In vivo measurement of cerebral oxygen consumption and blood flow using 170 magnetic resonance imaging. Magn Reson Med 1991;21(2):313-319.

126. Kwong KK, Hopkins AL, Belliveau JW, et al. Proton NMR imaging of cerebral blood flow using H2(17)O. Magn Reson Med 1991;22(1):154-158.

127. Hopkins AL, Lust WD, Haacke EM, Wielopolski P, Barr RG, Bratton CB. The stability of proton T2 effects of oxygen-17 water in experimental cerebral ischemia. Magn Reson Med 1991;22(1): $167-174$

128. Zhu XH, Zhang Y, Tian RX, et al. Development of (17)O NMR approach for fast imaging of cerebral metabolic rate of oxygen in rat brain at high field. Proc Natl Acad Sci U S A 2002;99(20): 13194-13199.

129. Zhang N, Zhu XH, Lei H, Ugurbil K, Chen W. Simplified methods for calculating cerebral metabolic rate of oxygen based on 170 magnetic resonance spectroscopic imaging measurement during a short $17 \mathrm{O} 2$ inhalation. J Cereb Blood Flow Metab 2004;24(8):840-848.

130. Zhu XH, Chen JM, Tu TW, Chen W, Song SK. Simultaneous and noninvasive imaging of cerebral oxygen metabolic rate, blood flow and oxygen extraction fraction in stroke mice. Neuroimage. 2013;64:437-447.

131. McCommis KS, He X, Abendschein DR, Gupte PM, Gropler RJ, Zheng J. Cardiac $17 \mathrm{O}$ MRI: toward direct quantification of myocardial oxygen consumption. Magn Reson Med 2010;63(6):14421447.

132. Atkinson IC, Thulborn KR. Feasibility of mapping the tissue mass corrected bioscale of cerebral metabolic rate of oxygen consumption using 17-oxygen and 23-sodium MR imaging in a human brain at 9.4 T. Neuroimage. 2010;51(2):723-733.

133. Cui W, Zhu XH, Vollmers ML, et al. Non-invasive measurement of cerebral oxygen metabolism in the mouse brain by ultra-high field (17)O MR spectroscopy. J Cereb Blood Flow Metab 2013;33(12):1846-1849.

134. Hoffmann SH, Radbruch A, Bock M, Semmler W, Nagel AM. Direct (17)O MRI with partial volume correction: first experiences in a glioblastoma patient. MAGMA 2014;27(6):579-587.

135. Gordji-Nejad A, Mollenhoff K, Oros-Peusquens AM, Pillai DR, Shah NJ. Characterizing cerebral oxygen metabolism employing oxygen-17 MRI/MRS at high fields. MAGMA. 2014;27(1):8193.

136. Zhu X-H, Zhang Y, Wiesner HM, Ugurbil K, Chen W. In vivo measurement of $\mathrm{CBF}$ using ${ }^{17} \mathrm{O}$ NMR signal of metabolically produced $\mathrm{H}_{2}{ }^{17} \mathrm{O}$ as a perfusion tracer. Magn Reson Med 2013;70(2):309-314.

137. Zhu XH, Zhang N, Zhang Y, Zhang X, Ugurbil K, Chen W. In vivo $17 \mathrm{O}$ NMR approaches for brain study at high field. NMR Biomed 2005;18(2):83-103.

138. Lou S, Lepak VC, Eberly LE, et al. Oxygen consumption deficit in Huntington disease mouse brain under metabolic stress. Hum Mol Genet 2016;25(13):2813-2826.

139. Kurzhunov D, Borowiak R, Reisert M, Joachim Krafft A, Caglar Özen A, Bock M. 3D CMRO2mapping in human brain with direct17O MRI: comparison of conventional and protonconstrained reconstructions. NeuroImage. 2017;155(May):612624. 
140. Kurzhunov D, Borowiak R, Hass H, et al. Quantification of oxygen metabolic rates in human brain with dynamic (17)O MRI: profile likelihood analysis. Magn Reson Med 2016;78(3):11571167.

141. Aguirre GK, Zarahn E, D'Esposito M. The variability of human, BOLD hemodynamic responses. Neuroimage. 1998;8(4):360369.

142. $\mathrm{Lu} \mathrm{H}, \mathrm{Ge}$ Y. Quantitative evaluation of oxygenation in venous vessels using T2-relaxation-under-spin-tagging MRI. Magn Reson Med 2008;60(2):357-363.

143. Xu F, Uh J, Brier MR, et al. The influence of carbon dioxide on brain activity and metabolism in conscious humans. J Cereb Blood Flow Metab 2011;31(1):58-67.

144. Chapman SB, Aslan S, Spence JS, et al. Shorter term aerobic exercise improves brain, cognition, and cardiovascular fitness in aging. Front Aging Neurosci 2013;5:75.

145. Kety SS, Schmidt CF. The nitrous oxide method for the quantitative determination of cerebral blood flow in man: theory, procedure and normal values. J Clin Invest 1948;27(4):476-483.

146. Cerdonio M, Morante S, Vitale S. Magnetic susceptibility of hemoglobins. Methods Enzymol 1981;76:354-371.

147. Li L, Leigh JS. Quantifying arbitrary magnetic susceptibility distributions with MR. Magn Reson Med 2004;51(5):1077-1082.

148. Jain V, Langham MC, Wehrli FW. MRI estimation of global brain oxygen consumption rate. J Cereb Blood Flow Metab 2010;30(9): 1598-1607.

149. Li C, Langham MC, Epstein CL, et al. Accuracy of the cylinder approximation for susceptometric measurement of intravascular oxygen saturation. Magn Reson Med 2012;67(3):808-813.

150. $\mathrm{Xu} \mathrm{F}, \mathrm{Ge} \mathrm{Y}, \mathrm{Lu} \mathrm{H}$. Noninvasive quantification of whole-brain cerebral metabolic rate of oxygen (CMRO2) by MRI. Magn Reson Med 2009;62(1):141-148.

151. Bulte DP, Kelly M, Germuska M, et al. Quantitative measurement of cerebral physiology using respiratory-calibrated MRI. Neuroimage. 2012;60(1):582-591.

152. Lee JM, Vo KD, An H, et al. Magnetic resonance cerebral metabolic rate of oxygen utilization in hyperacute stroke patients. Ann Neurol 2003;53(2):227-232.

153. Lin YJ, Koretsky AP. Manganese ion enhances T1-weighted MRI during brain activation: an approach to direct imaging of brain function. Magn Reson Med 1997;38(3):378-388.

154. Pautler RG, Koretsky AP. Tracing odor-induced activation in the olfactory bulbs of mice using manganese-enhanced magnetic resonance imaging. Neuroimage. 2002;16(2):441-448.

155. Li W-H, Fraser SE, Meade TJ. A calcium-sensitive magnetic resonance imaging contrast agent. J Am Chem Soc 1999;121(6): 1413-1414.

156. Atanasijevic T, Shusteff M, Fam P, Jasanoff A. Calcium-sensitive MRI contrast agents based on superparamagnetic iron oxide nanoparticles and calmodulin. Proc Natl Acad Sci U S A 2006;103(40): 14707-14712.

157. Golman K, in't Zandt R, Thaning M. Real-time metabolic imaging. Proc Natl Acad Sci. 2006;103(30):11270.

158. Cai K, Haris M, Singh A, et al. Magnetic resonance imaging of glutamate. Nat Med 2012;18(2):302-306.

159. Bagga P, Pickup S, Crescenzi R, et al. In vivo GluCEST MRI: reproducibility, background contribution and source of glutamate changes in the MPTP model of Parkinson's disease. Sci Rep 2018;8(1):2883.

160. Rodrigues TB, Gray HL, Benito M, et al. Futile cycling of lactate through the plasma membrane of $\mathrm{C} 6$ glioma cells as detected by (13C, 2H) NMR. J Neurosci Res 2005;79(1-2):119-127.

161. Zhu X-H, Lu M, Chen W. Quantitative imaging of brain energy metabolisms and neuroenergetics using in vivo X-nuclear $2 \mathrm{H}$, $17 \mathrm{O}$ and 31P MRS at ultra-high field. J Magn Reson 2018;292: $155-170$.
162. De Feyter HM, Behar KL, Corbin ZA, et al. Deuterium metabolic imaging (DMI) for MRI-based 3D mapping of metabolism in vivo. Sci Adv. 2018;4(8):eaat7314.

163. Hanaoka K, Kikuchi K, Urano Y, et al. Design and synthesis of a novel magnetic resonance imaging contrast agent for selective sensing of zinc ion. Chem Biol 2002;9(9):1027-1032.

164. Que EL, Chang CJ. A smart magnetic resonance contrast agent for selective copper sensing. J Am Chem Soc 2006;128(50):1594215943.

165. Zhang X-A, Lovejoy KS, Jasanoff A, Lippard SJ. Water-soluble porphyrins as a dual-function molecular imaging platform for MRI and fluorescence zinc sensing. Proc Natl Acad Sci. 2007;104(26):10780.

166. Tsang A, Stobbe RW, Beaulieu C. Triple-quantum-filtered sodium imaging of the human brain at 4.7 T. Magn Reson Med 2012;67(6):1633-1643.

167. Fleysher L, Oesingmann N, Brown R, Sodickson DK, Wiggins $\mathrm{GC}$, Inglese M. Noninvasive quantification of intracellular sodium in human brain using ultrahigh-field MRI. NMR Biomed 2013;26(1):9-19.

168. Chesler M. Regulation and modulation of $\mathrm{pH}$ in the brain. Physiol Rev 2003;83(4):1183-1221.

169. Garcia-Martin ML, Martinez GV, Raghunand N, Sherry AD, Zhang S, Gillies RJ. High resolution pHe imaging of rat glioma using pH-dependent relaxivity. Magn Reson Med 2006;55(2): 309-315.

170. Raghunand N, Howison C, Sherry AD, Zhang S, Gillies RJ. Renal and systemic $\mathrm{pH}$ imaging by contrast-enhanced MRI. Magn Reson Med 2003;49(2):249-257.

171. Raghunand N, Zhang S, Sherry AD, Gillies RJ. In vivo magnetic resonance imaging of tissue $\mathrm{pH}$ using a novel $\mathrm{pH}$-sensitive contrast agent, GdDOTA-4AmP. Acad Radiol 2002;9(2):S481-S483.

172. Zhou J, Payen J-F, Wilson DA, Traystman RJ, van Zijl PCM. Using the amide proton signals of intracellular proteins and peptides to detect $\mathrm{pH}$ effects in MRI. Nat Med 2003;9(8):1085-1090.

173. Weissleder R, Moore A, Mahmood U, et al. In vivo magnetic resonance imaging of transgene expression. Nat Med 2000;6(3): 351-355.

174. Louie AY, Hüber MM, Ahrens ET, et al. In vivo visualization of gene expression using magnetic resonance imaging. Nat Biotechnol 2000;18(3):321-325.

175. Bulte JW, Douglas T, Witwer B, et al. Magnetodendrimers allow endosomal magnetic labeling and in vivo tracking of stem cells. Nat Biotechnol 2001;19(12):1141-1147.

176. Gilad AA, McMahon MT, Walczak P, et al. Artificial reporter gene providing MRI contrast based on proton exchange. Nat Biotechnol 2007;25(2):217-219.

177. Genove G, DeMarco U, Xu H, Goins WF, Ahrens ET. A new transgene reporter for in vivo magnetic resonance imaging. Nat Med 2005;11(4):450-454.

178. Kleinridders A, Ferris HA, Reyzer ML, et al. Regional differences in brain glucose metabolism determined by imaging mass spectrometry. Mol Metab 2018;12:113-121.

179. Mergenthaler P, Lindauer U, Dienel GA, Meisel A. Sugar for the brain: the role of glucose in physiological and pathological brain function. Trends Neurosci 2013;36(10):587-597.

180. Quintard H, Patet C, Zerlauth JB, et al. Improvement of neuroenergetics by hypertonic lactate therapy in patients with traumatic brain injury is dependent on baseline cerebral lactate/ pyruvate ratio. J Neurotrauma 2016;33(7):681-687.

181. Carteron L, Patet C, Solari D, et al. Non-ischemic cerebral energy dysfunction at the early brain injury phase following aneurysmal subarachnoid hemorrhage. Front Neurol 2017;8:325.

182. Bouzat P, Sala N, Payen JF, Oddo M. Beyond intracranial pressure: optimization of cerebral blood flow, oxygen, and substrate 
delivery after traumatic brain injury. Ann Intensive Care 2013;3(1):23

183. Cesak T, Adamkov J, Habalova J, et al. The relationship between intracranial pressure and lactate/pyruvate ratio in patients with subarachnoid haemorrhage. Bratisl Lek Listy 2018;119(3):139142 .

184. Murr R, Stummer W, Schurer L, Polasek J. Cerebral lactate production in relation to intracranial pressure, cranial computed tomography findings, and outcome in patients with severe head injury. Acta Neurochir 1996;138(8):928-936; discussion 36-7.

185. Mathupala SP, Colen CB, Parajuli P, Sloan AE. Lactate and malignant tumors: a therapeutic target at the end stage of glycolysis. J Bioenerg Biomembr 2007;39(1):73-77.

186. Bergersen LH. Lactate transport and signaling in the brain: potential therapeutic targets and roles in body-brain interaction. J Cereb Blood Flow Metab 2015;35(2):176-185.

187. Malkov A, Ivanov AI, Latyshkova A, Bregestovski P, Zilberter M, Zilberter Y. Activation of nicotinamide adenine dinucleotide phosphate oxidase is the primary trigger of epileptic seizures in rodent models. Ann Neurol 2019;85(6):907-20.

188. Bernini A, Masoodi M, Solari D, et al. Modulation of cerebral ketone metabolism following traumatic brain injury in humans. J Cereb Blood Flow Metab 2020;40(1):177-186.

189. Eiden M, Christinat N, Chakrabarti A, et al. Discovery and validation of temporal patterns involved in human brain ketometabolism in cerebral microdialysis fluids of traumatic brain injury patients. EBioMedicine. 2019;44:607-617.

190. Maalouf M, Sullivan PG, Davis L, Kim DY, Rho JM. Ketones inhibit mitochondrial production of reactive oxygen species production following glutamate excitotoxicity by increasing NADH oxidation. Neuroscience. 2007;145(1):256-264.

191. Bazzigaluppi P, Lake EM, Beckett TL, et al. Imaging the effects of beta-hydroxybutyrate on peri-infarct neurovascular function and metabolism. Stroke. 2018;49(9):2173-2181.

192. Nasrallah FA, Garner B, Ball GE, Rae C. Modulation of brain metabolism by very low concentrations of the commonly used drug delivery vehicle dimethyl sulfoxide (DMSO). J Neurosci Res 2008;86(1):208-214.

193. Barreto G, White RE, Ouyang Y, Xu L, Giffard RG. Astrocytes: targets for neuroprotection in stroke. Cent Nerv Syst Agents Med Chem 2011;11(2):164-173.

194. Wijman CA, Smirnakis SM, Vespa P, et al. Research and technology in neurocritical care. Neurocrit Care 2012;16(1):42-54.

195. Medaglia JD. Functional neuroimaging in traumatic brain injury: from nodes to networks. Front Neurol 2017;8:407.

196. Gu Y, Wang CY, Anderson CE, et al. Fast magnetic resonance fingerprinting for dynamic contrast-enhanced studies in mice. Magn Reson Med 2018;80(6):2681-2690.

197. Liu Y, Zhang Y, Wu C, et al. High-resolution dynamic oxygen-17 MR imaging of mouse brain with golden-ratio-based radial sampling and k-space-weighted image reconstruction. Magn Reson Med 2018;79(1):256-263.

198. Zhang Y, Xu K, Liu Y, et al. Increased cerebral vascularization and decreased water exchange across the blood-brain barrier in aquaporin-4 knockout mice. PLoS One 2019;14(6):e0218415.

199. Ohtsuki S, Terasaki T. Contribution of carrier-mediated transport systems to the blood-brain barrier as a supporting and protecting interface for the brain; importance for CNS drug discovery and development. Pharm Res 2007;24(9):1745-1758.

200. Tsuji A. Small molecular drug transfer across the blood-brain barrier via carrier-mediated transport systems. NeuroRx. 2005;2(1): 54-62.

201. Reivich M, Kuhl D, Wolf A, et al. The [18F] fluorodeoxyglucose method for the measurement of local cerebral glucose utilization in man. Circ Res 1979;44(1):127-137.

202. de Backer ME, Nabuurs RJ, van Buchem MA, van der Weerd L. MR-based molecular imaging of the brain: the next frontier. AJNR Am J Neuroradiol 2010;31(9):1577-1583.

Publisher's Note Springer Nature remains neutral with regard to jurisdictional claims in published maps and institutional affiliations. 